محددات ونتائج تحسين بيئة المعلومات

في الشركــات المصريـة الصغيـرة والمتوسطـة الحجـــ

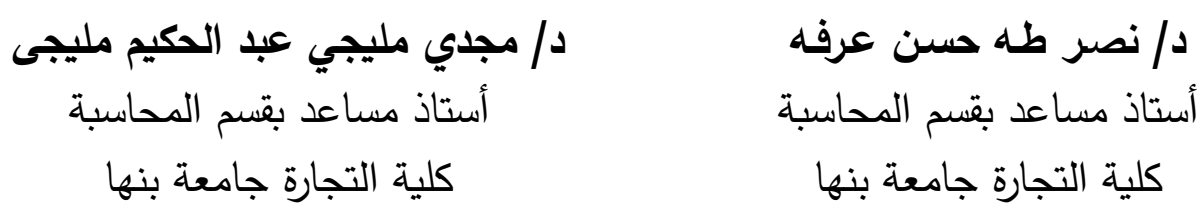


محدات ونتائج تحسين بيئة المعلومات في الثركات المصرية الصغيرة وإلمتوسطة الحجم

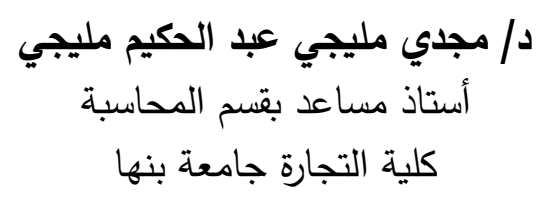

د/ نصر طه حسن عرفه

أستاذ مساعد بقسم المحاسبة

كلية التجارة جامعة بنها

\section{ملخص البحث:}

تهدف الدراسة الحالية إلى توضيح أهمية تطوير بيئة معلومات الثركات الصغيرة والمتوسطة الحجم

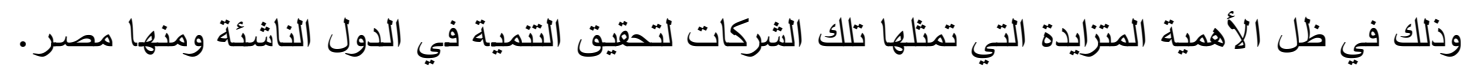

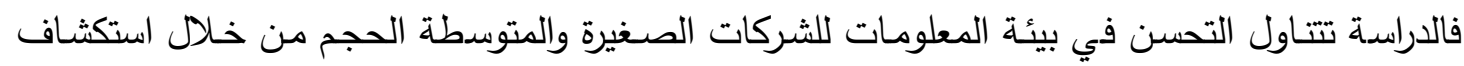

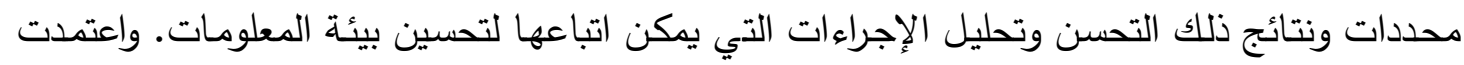

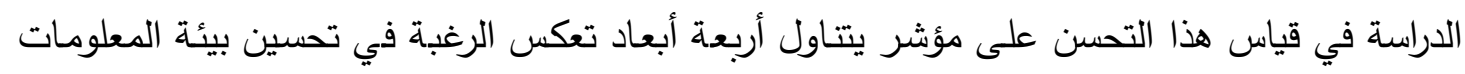

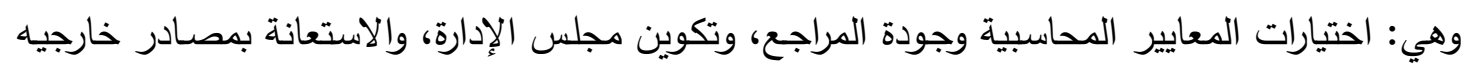

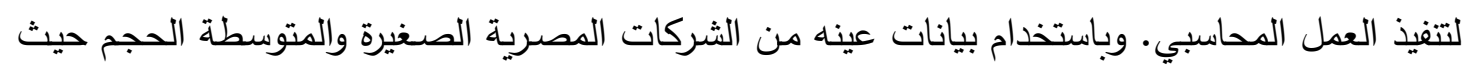

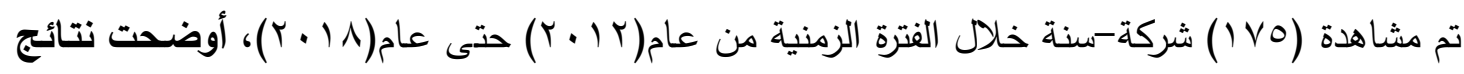

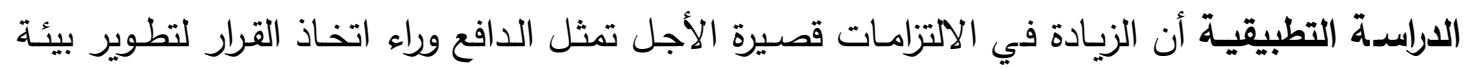
المعلومـات، وأن ذلك التطوير يسـاعد الشـركة في مواجهة تحديات التمويـل التي تواجهها حيث تلتيح للشركة الوصول إلى مصادر التمويل طويلة الأجل وتخفض من تكلفة الدين. واستنادًا إلى ذلك توصي توصي

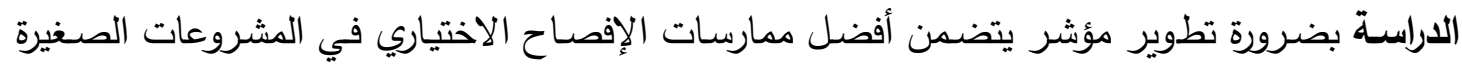
والمتوسطة وترتبها في الأفضلية وفقًا لذلك، وإصدار دليل خاص بحتئ بحوكمة هذه المشروعات، بالإضـافة

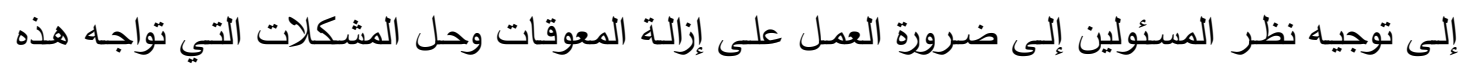

$$
\text { المشروعات. }
$$

وتتمثل أهمية نتائج الدراسدة في عدة مستويات، فعلى مستوى الشركات الصغيرة والمتوسطة الحجم

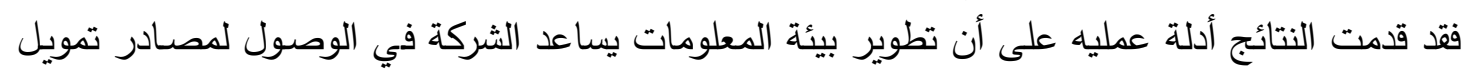

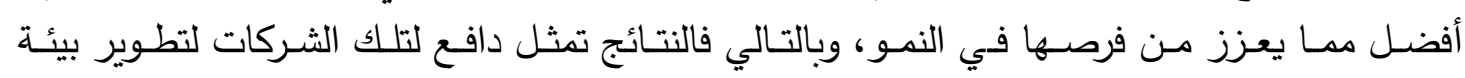

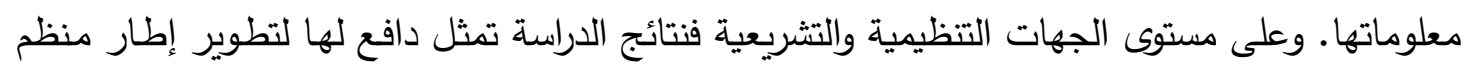

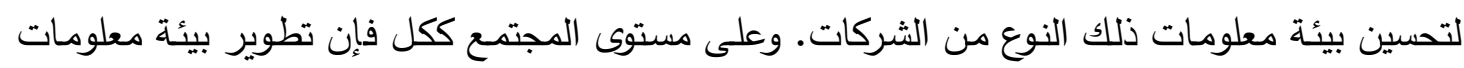

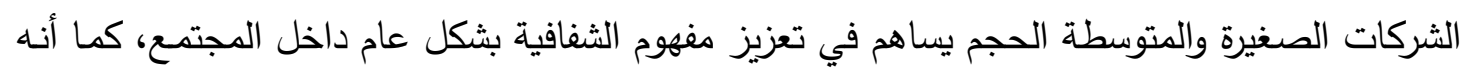
يعزز من فرص تلك الثركات في الاستمرار والنمو وهو ما يمثل أهمية كبيره على المستوى القومي. أما فيا

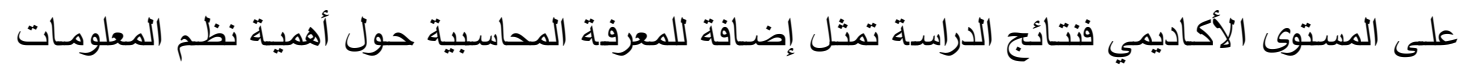
المحاسبية في الثركات الصغيرة والمتوسطة الحجم.

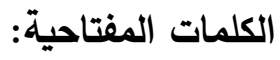

معيار المحاسبة للمنشآت الصـغيرة والمتوسطة، الإسـناد الخـارجي لوظـائف المحاسبة، جـودة المراجعة، استقلال مجلس الإدارة؛ تكلفة الدين، مصادر التمويل طويلة الأجل، الديون طويلة الأجل. 


\title{
Determinants and Consequences of Improvements in the Information Environment for Egyptian Small and Mid-Sized Firms
}

\author{
Dr. Nasr Taha Hassan \\ Assistant Professor, Department \\ of Accounting Faculty of Commerce, \\ Benha University
Dr. Magdy Melegy Abdulhakim Melegy
Assistant Professor, Department of Accounting Faculty of Commerce, Benha University

\begin{abstract}
:
This study aims to clarify the importance of improvement of the information environment of small and medium-sized firms consistent with the increasing importance they represent to achieve development in emerging countries, including Egypt. The study addresses the improvement in the information environment of SMEs by exploring the determinants and consequences of that improvement and analyzing the procedures that can be taken to improve the information environment. To measure the improvement of information environment, the study use indicator consisting of four elements; choices of accounting standards, audit quality, the composition of the Board of Directors and outsourcing accounting work. The results showed that the increase in current liabilities represents the motivation to improve the information environment. This improvement helps the company face the financing challenges it faces, allowing the company to access long-term financing sources and reduce the cost of debt. Based on these results, the researchers recommends to establish an disclosure index that includes best practices for voluntary disclosure in SMEs and rank them in order of preference, and the issuance of a governance guide for the of these projects, in addition to pay attention to remove obstacles and solve problems facing these projects.

The importance of study can be explained ate different levels; for SMEs, the results provide empirical evidence concerning the importance of information environment, which drive these companies to improve their information environment. For regulatory and legislative bodies, the results of study motivate them to develop a regulatory framework to improve the information environment of that type of companies. for society as a whole, the development of the SME information environment contributes to the promotion of the concept of transparency in general within the community, and enhances the opportunities of these companies to continue and grow, which is of great importance at the national level. At the academic level, the results of the study represent an addition to accounting knowledge about the importance of accounting information systems in small and medium-sized companies.
\end{abstract}

\section{Keywords:}

Accounting Standard for SMEs, Outsourcing of Accounting Functions, Audit Quality; Board Independence; Cost of Debt; Long Term Sources of Finance; Long Term Debt. 


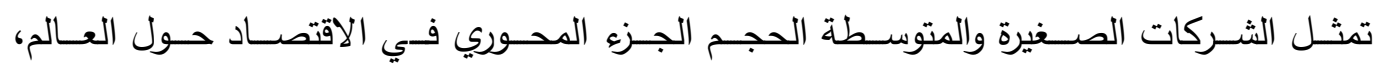

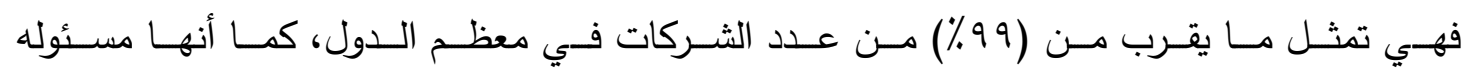

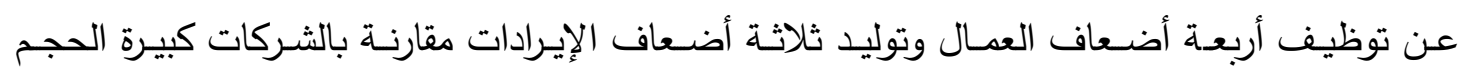

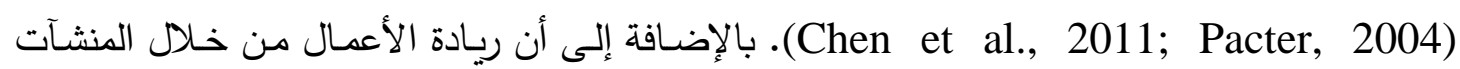

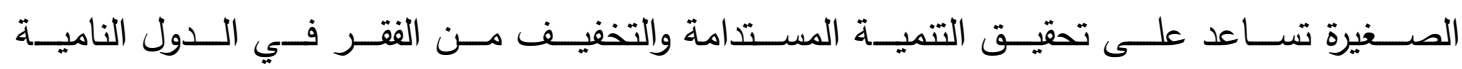
(Tilley \& Parrish, 2006)، فالثركات الصغيرة والمتوسطة الحجم وأنشطة ريادة الأعمال لها أهمية محوريه في تطوير أي اقتصاد (Esuh \& Adebayo, 2012). وبالرغم من تلك الأهمية فهناك اهتمام

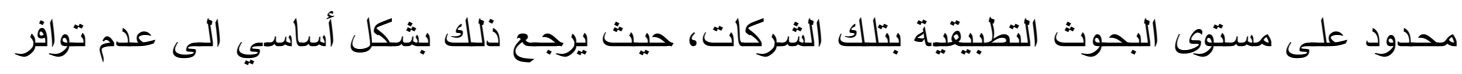

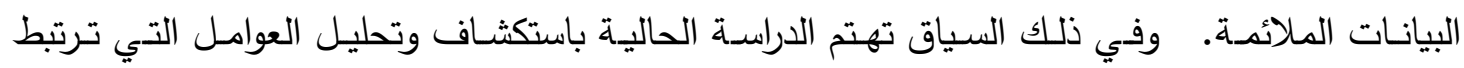

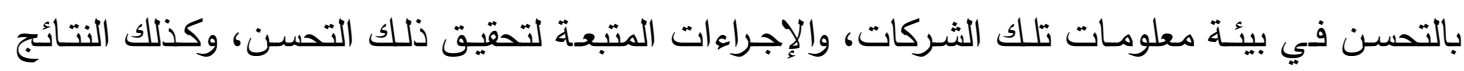

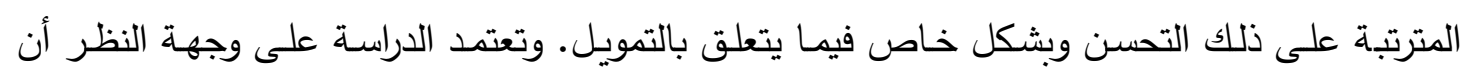

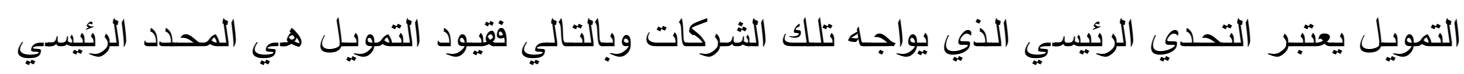

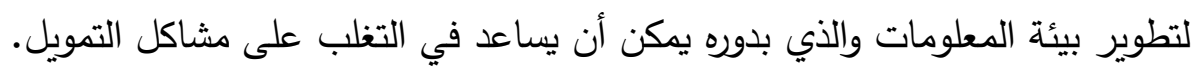

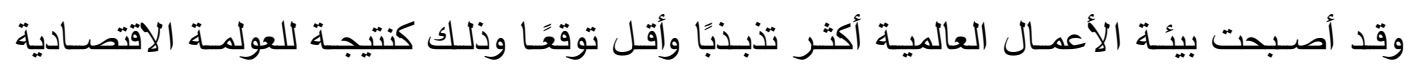

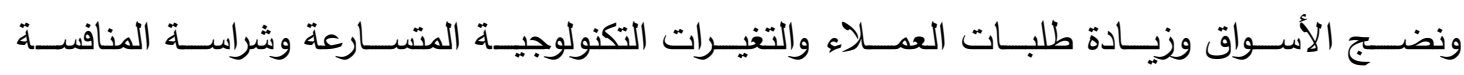

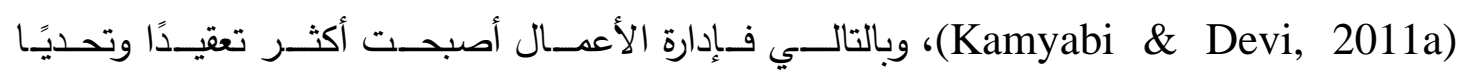
(Lamminmaki, 2007; Espino-Rodríguez \& Padrón-Robaina, 2004)

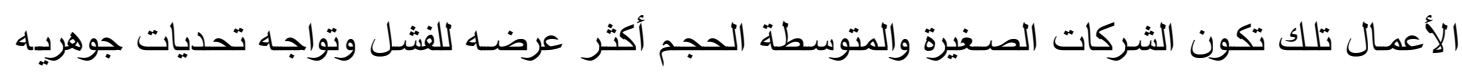

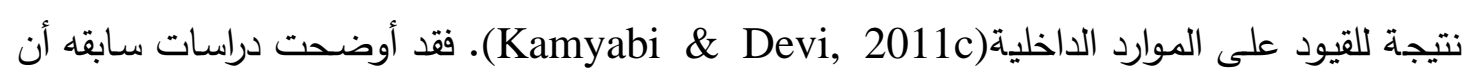

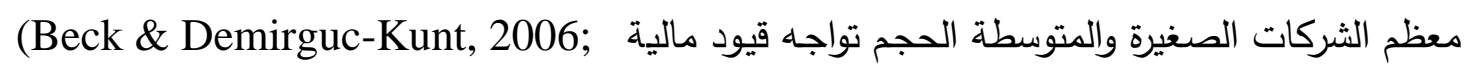
وأن هناك عدم تماثل معلومات بين الsقرضين والمقترضين يحد من استعداد المقرضين لتوفير التمويل (Coluzzi et al. 2012).

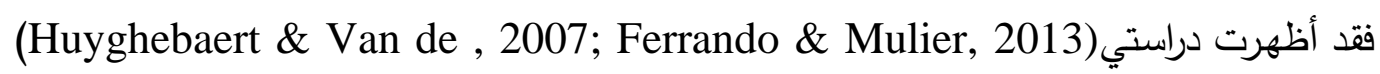

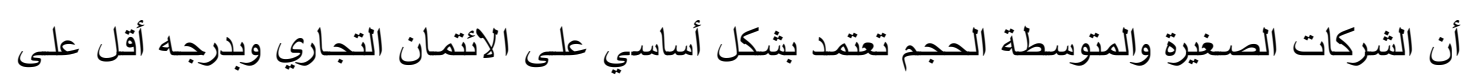

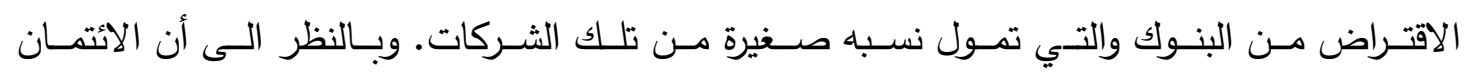
التجاري أحد أكثر أشكال التمويل الخارجي تكلفه (Petersen \& Rajan, 1994; Wilner, 2000)

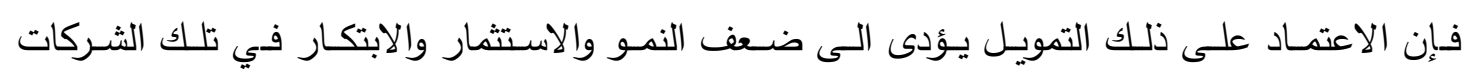

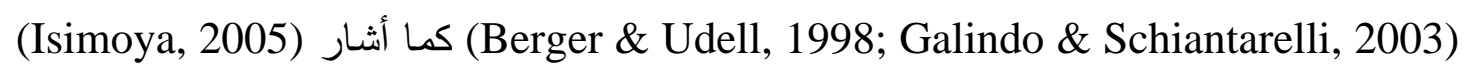
إلى أنه من المشاكل التي تهدد عمل الشركات صغيرة ومتوسطة الحجم محدودية الوصول لمصـادر

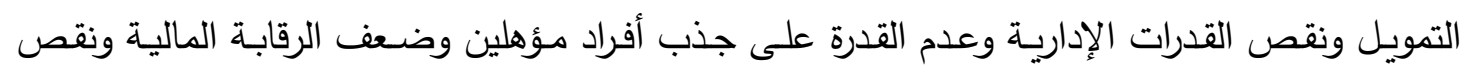

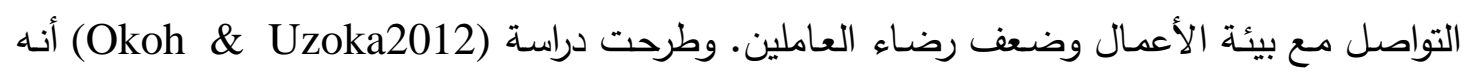


نظرًا لان نقص التمويل مـن العوامل التي تعوق عمل الثـركات صـغيرة ومتوسطة الحجم، فاستخدام المعلومات المحاسبية واختيارات التمويل تعتبر من الأمور التي يجب الاهتمام بها لعمل واستمرار تلك الشركات بكفاءة.

وتلعبب المعلومـات المحاسبية دور هـام في تحسين أداء الشـركات الصـغيرة حيث تمثل أداه للرقابـة

وتساعد في المعاملات الائتمانية والأمور الضريبية بالإضـافة لتحديد الربح (Okoh\&Uzoka2012)

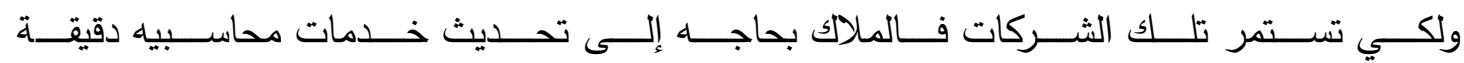
(Nwobu, et al. 2015). وقد أشارت بعض الدراسات الى أن جودة وتوافر المعلومات المالية من ضـــن العوامـل التـي تـؤثر فـي هيكـل راس المـال وتكلفـة الـدين للشـركات صــيرة ومتوسـطة الحجـم (Garcia-Teruel \& Martinez-Solano, 2007; Eierle, 2008; Minnis, 2011; Van Caneghem \& Van Campenhout, 2012; Luyapert, 2015; Vander كما وجدت بعض الدراسات أن الشركات صغيرة ومتوسطة الحجم التي $B a w$ مي (Minnis, 2011; Kim at al. 2011; لديها قوائم ماليه تمت مراجعتها تكون تكلفة الدين لديها اقل وقامت دراسة (Bharath, et al., 2008) باختبار تأثير جودة \&uguet \& Gandia, 2014).

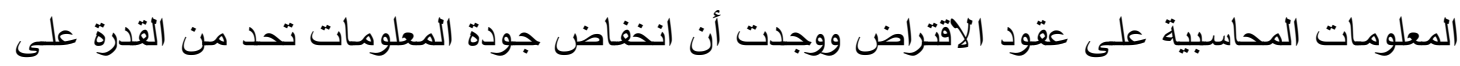
التتبؤ بالتدفقات النقدية للشركة التي تبحث عن الائتمان مما ينعكس بالزيادة على تكلفة راس المال.

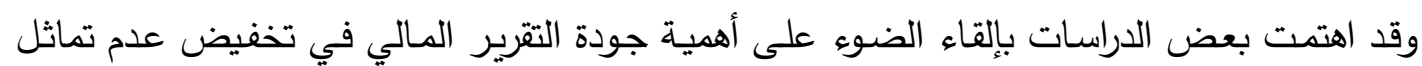
(Allee \& Yohn, 2009; المعلومات بيـن الثركــات صغيـرة و متوسطـة الحجـم ودائنيها Cassar et al., 2010; Hope et al., 2011; Collis, 2012; Moro et al., 2014; وبشكل خاص لحاجة تلك الثركات للاقتراض في ظل صعوبة وصولها لأسواق المال (Berger \& Udell, 2002, Newman et al. 2012). فمحدودية الائتمان أحد (Carvalho \& Abramovay, 2004; المشاكل التي تواجه الشركات صـغيرة ومتوسطة الحجم Ortiz-Molina \&Penas, 2008; Binks \& Ennew, 1996; Van Caneghem \& Van وفي هذا السيـاق فالمحاسبـة تلعـب دور في توفـير الثفافيــة حيــث أن \&ampenhout, 2012)

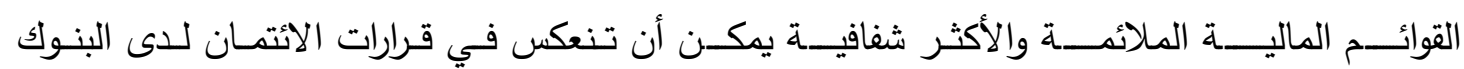

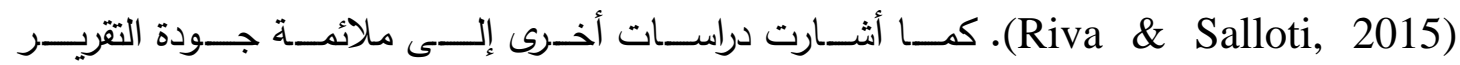
(Minnis, 2011; Hope et al. 2013; Vander المالي في تخفيض تكلفة الدين لتلك الشركات Bauwhede et al., 2015) وقد وجد تقرير مجلس التقرير المالي (FRC) أن مستثمري المنثآت صغيرة وكبيرة الحجم يرون أن جودة التقرير المالي عامل جوهري في قرارات الاستثمار بينما ينظر إليه المديرين على إنه مجرد ممارسـ للالتزام Financial Reporting Council (June, 2015) أشـارت دراسـة (Morris \& Omrod, 1990) \& Oلى أن توفير الثـركات الصـغيرة للمعلومـات يعتبر مصدر هام لتقييم خطر الأتمان. وقد أوضحت (Kitching et al.,2011) أن معلومات الشركة تقدم رؤية محدودة للمركز والأداء المالي للشركة وأن هناك معلومات أخرى بجانبها تكون مطلوبة لتقييم خطر الائتمان. ومن المحتمل أن 
مديري الشركات الصغيرة يدركوا ذلك وأنهم يقوموا بتوفير معلومات تمت مراجعتها على اساس اختياري وذلك لتحسين تصنيفهم الأتماني (Collis 2003, Marriott et al. 2006). وبالرغم من أن كل من الدراسات الأكاديمية والمنظمات المهنية تؤكد على أهمية جودة التقرير المالي للشركات صـغيرة ومتوسطة الحجم، وبـالرغم من أهميـة تلك الثـركات على مستوى الاقتصـاد العالمي والاهتمـام المتزايـد بالمعلومـات الماليـة لـديها بعـد إصــار معـايير (IFRS) لتلك الثـركات في عـام

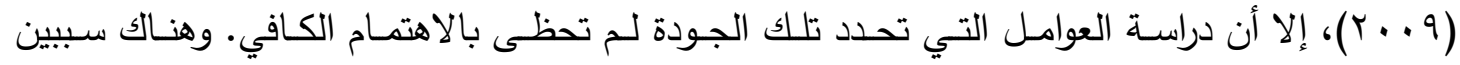

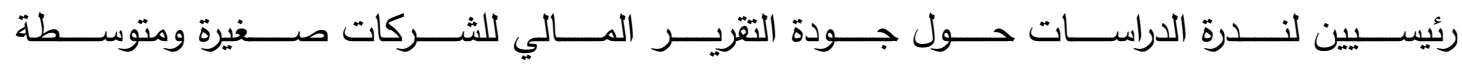

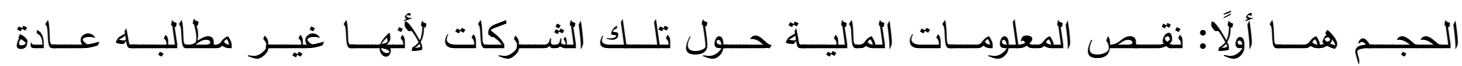

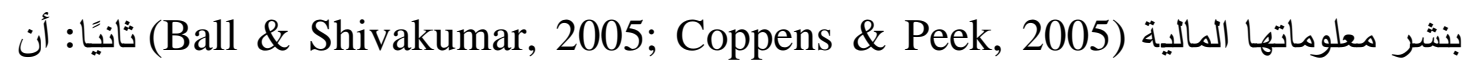

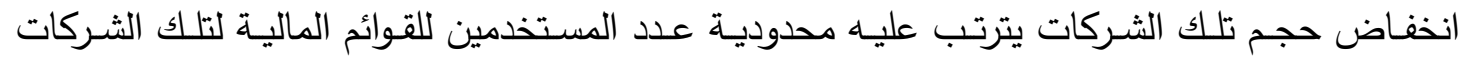
(McMahon, 1999; Evans et al., 2005; Son et al., 2006; Sian \& Roberts, 2009; مما يجعل مشكلة الوكالة أقل وضوحًا في ذلك السياق. علاوة على Rennie \& Senkow, 2009), ذلك فمن وجهة نظر الحوكمة فإن مشكلة الوكالة في الشركات صغيرة ومتوسطة الحجم تختلف عن

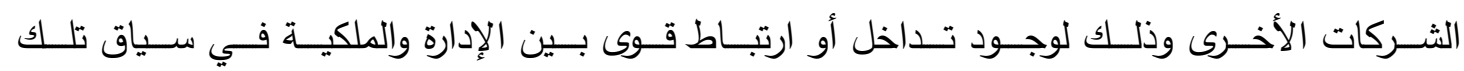

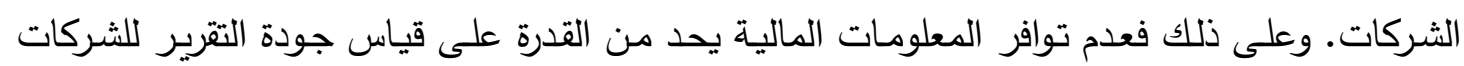

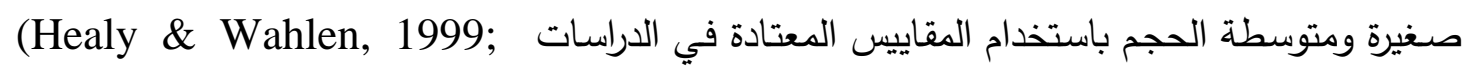
كمـا أن انخفاض ملائمـة مشكلة الوكالة قد يغير من الدوافع التقليديـة Dechow et al., 2010) للتلاعب بالقوائم المالية بما يضر بجودة التقرير المالي (Ball \& Shivakumar, 2005).

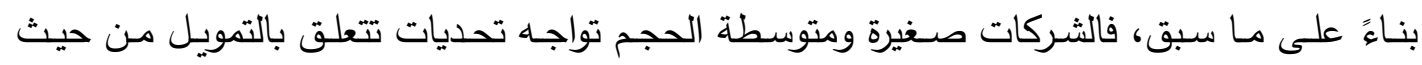
صعوبة الوصول لمصادر التمويل طويل الأجل وارتفاع تكلفة الدين، وفي هذا السياق فالمعلومات يمكن لون أن تلعب دور هـام لمسـاعدة تلك الثـركات في مواجهة تلك التحديات بمـا يعكس أهميـة تطوير بيئة

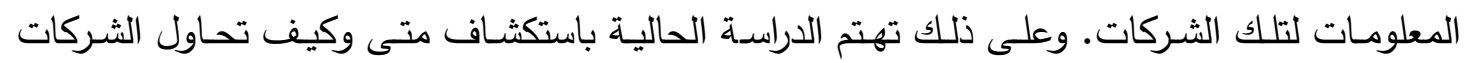
صغيرة ومتوسطة الحجم تحسين بيئة المعلومات الخاصة بها وكيف يؤثر ذلك في وصول تلك الثركات إلى تمويل البنوك وعلى تكلفة الدين. وبالتالي فالدراسة تهذف لتقديم ادله عمليه من الثركات المصرية للإجابة عن الأسئلة التالية:

1- هل تؤدى الزيادة في الالتزامات قصيرة الأجل إلى اتجاه الثركة لتحسين بيئة المعلومات لديها؟

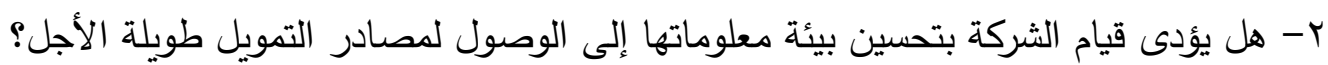
r- هل يؤدى قيام الشركة بتحسين بيئة معلوماتها إلى تخفيض تكلفة الدين؟ ونظرًا لوجود طرق مختلفة يمكن أن تستخدمها الشركة لتحسين بيئة المعلومات لديها، تعتمد الدراسـة على مؤشر يتضمن المعايير المحاسبية وجودة المراجع وخصـائص مجلس الإدارة والاستعانة بمصدر خارجي لأداء المهام المحاسبية للتعبير عن التحسن في بيئة معلومات الثركة. حيث تتـاول الدراسـة الاختيارات المباشـرة لتحسين بيئة المعلومـات عن طريق زيـادة جودة التقرير المـالي من خـلال تطبيق 
معايير (IFRS) و /أو الاستعانة بمصادر خارجيه لتتفيذ الأنشطة المحاسبية، والاختيارات غير المباشرة

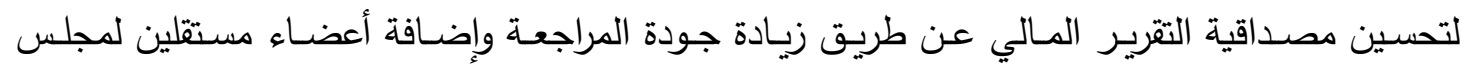
الإدارة.

وتنبـع أهميـة الاراسـة مـن الأهميـة الكبيرة والمتزايدة للشـركات صـغيرة ومتوسطة الحجم في بيئة الأعمال العالمية بشكل عام وبيئة الأعمال المصرية بشكل خاص وتحديدًا في الفترة الحالية التي يمر

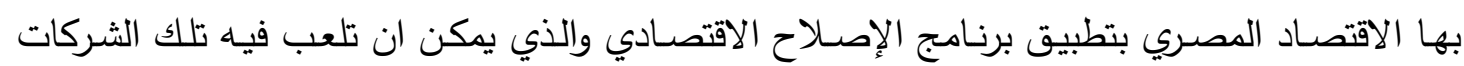
دور محوري. وعلى المستويين الأكاديمي والتطبيقي تتمثل أهمية الدراسـة في عدة نقاط: أولاًا: توضح نتائج الدراسة للشركات صغيرة ومتوسطة الحجم كيف يمكن تخفيض تكاليف التمويل والوصول لمصسادر الاقتراض طويل الأجل، وهو ما يعتبر أمر هام لتلك الثركات والتي تعاني من قيود على التمويل تحد من فرص الاستثمار والنمو. ثانيًا: إلقاء الضوء على أهمية التقرير المالي للشركات صغيرة ومتوسطة الحجم وأنه يمكن استخدامه بواسطة المقرضين، بالإضـافة إلى أهمية جودة المراجع. ثالثًا: تقدم الدراسـة رؤيسة أكثر تكاملًا لبيئة معلومات الثركات صغيرة ومتوسطة الحجم من خـلال تتاول محددات ونتائج والإجراءات المتخذة لتحسين تلك البيئة، واستخدام مؤشر متعدد الأبعاد للتعبير عن التحسن في بيئة المعلومات. رابعًا: تساهم الدراسة للأدب المتعلق بالمراجعة من خلال توضيح العلاقة بين كفاءة المراجعة

وتكلفة الدين.

ويتم استكمال الاراسة بالشكل التالي: يتتاول القسم الثاني: تحليل للإجراءات التي يمكن اتباعها لتحسين بيئة معلومات الثركات صغيرة ومتوسطة الحجم، ويتناول القسم الثالث: الدراسات السابقة وتطوير فروض الدراسة، أما القسم الرابع: فيقدم تصميم الدراسة ومنهج البحث بينما يعرض القسم الخامس لنتائج الدارسة التطبيقية وتختتم الاراسة بالنتائج والتوصيات وحدود الدراسة واقتراحات الدراسات المستقبلية.

\section{r- تحسين بيئة معلومات الشركات صغيرة ومتوسطة الحجم:}

أشـارت دراسـات سـابقة إلـى بيئة المعلومـات على أنهـا المعلومـات المتاحـة لتقيـيم مركز الثـركة

(Byard et al., 2011; Horton et al., 2013; Kang et al., 2012; والفرص المستقبلية وتتيح للإدارة توصيل معلومات مفيدة للأطراف الخارجية ومساعدتهم في تقييم تلك المعلومات (Paananen, et al. 2016). وتتناول الدراسة الحالية دور المعلومات في الشركات صغيرة ومتوسطة الحجم وذلك من خلال الآليات التي يمكن أن تتبعها تلك الثركات لتحسين بيئة المعلومات لديها. أولى تلك الأليات: هو اختيار المعايير المحاسبية، حيث يمكن اعتبار القرار باستخدام معايير التقرير المـالي الدولية للشـركات الصـغيرة (IFRS) كقرار مباشـر لتحسين بيئة المعلومـات، فقد أشـارت (Barth et al., 2008; يؤدى لزيادة جودة المحاسبة (IFRS) (العديد من الدراسات إلى أن تطبيق معايير (IFR) Daske et al., 2008; Brüggemann et al., 2013; Glaum et al., 2013). معايير المحاسبة الدولية (IASB) في إطار التوجه نحو تحقيق الاتساق والتجانس بين الشركات صغيرة 


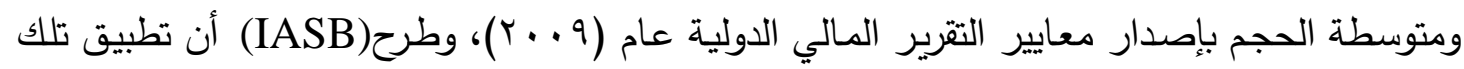
المعايير يحسن من فرص الثركات صغيرة ومتوسطة الحجم في الوصول للتمويل من خلال المعلومات

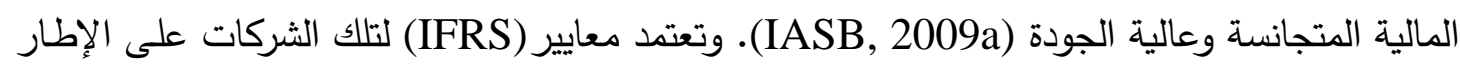
الكامل لمعايير التقرير المالي الدولية مع بعض التعديلات التي تعكس احتياجات من يستخدمون قوائمها

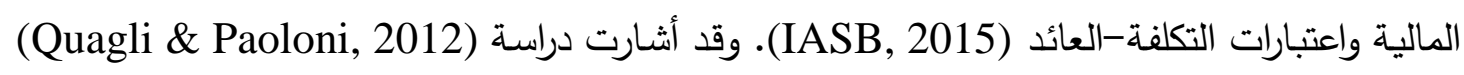

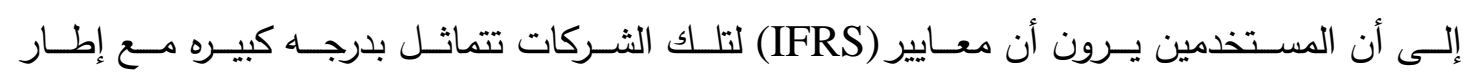
معايير (IFRS) الكامل، إلا أن الإطـار الكامل للمعايير الدوليـة يعتبر مجموعـه من المعايير المعقدة والمكلفة بالنسبة للشركات صغيرة ومتوسطة الحجم (IASB) (Perera\& Chand, 2015).

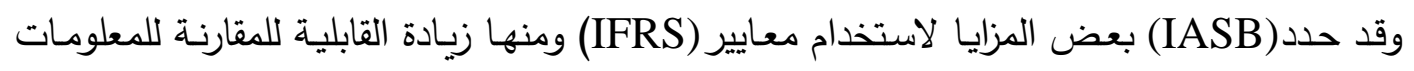

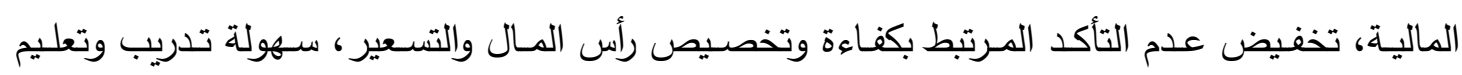

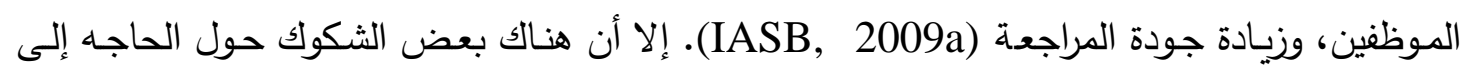

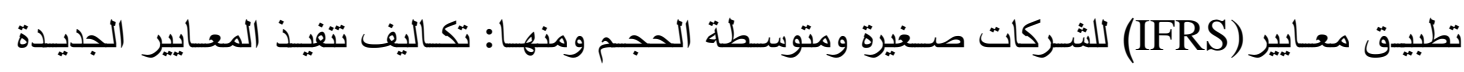
(Neag, Masca, \& Pascan, 2009; Wright et al., 2012; Litjens, Bissessur, Langendijk， \& Vergoossen, 2012) (Herman, 2010; Bertoni \& De Rosa, المصلحة لتلك الثركات فيما يتعلق بتنفيذ تلك المعايير الاخري 2010; Wright et al., 2012; Lenormand, et al. 2012) التلك الشركات (Herman, 2010; Neag et al., 2009; Pacter, 2009) وكذلك تحديد مستخدمي

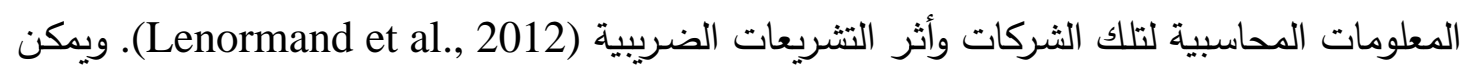

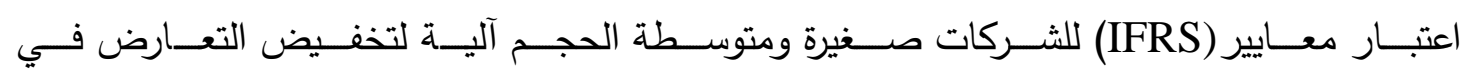

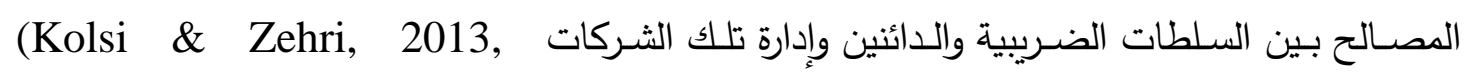
Christensen et al., 2009)

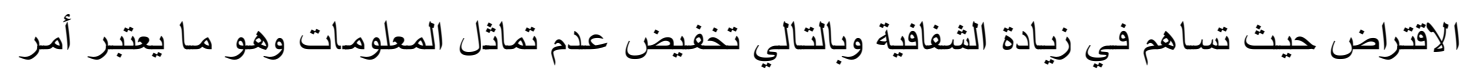

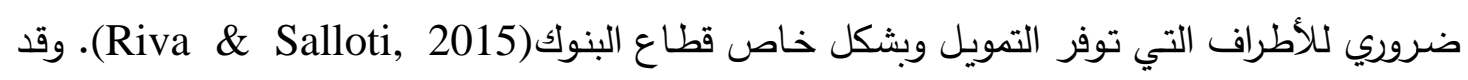
قامت دراسة (2017) Lang\& Martin باختبار ما إذا كان معايير (IFRS) يؤدى لتطوير المعالجات التبات

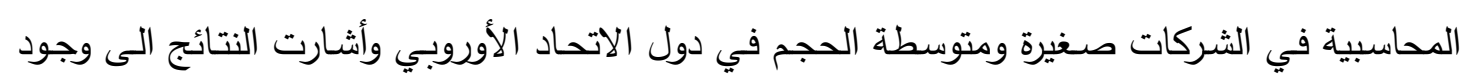
ذلك التأثير .

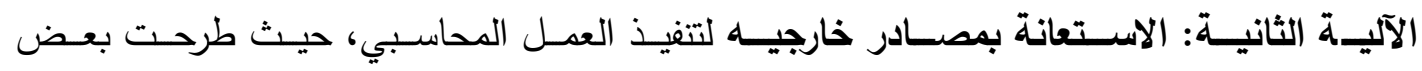

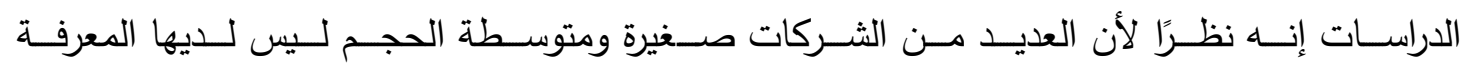

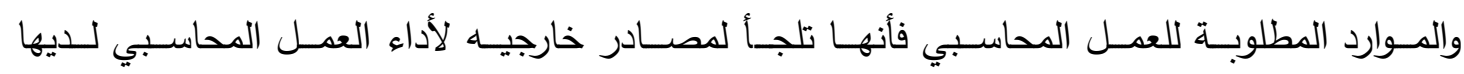
(Everaert, Sarens, \&Rommel, 2007; Niemi, Kinnunen, Ojala, \& Troberg, 2012; فللتغلب على الصعوبات التي تواجه الشركات Ojala, Niskanen, Collis, \& Pajunen, 2014).

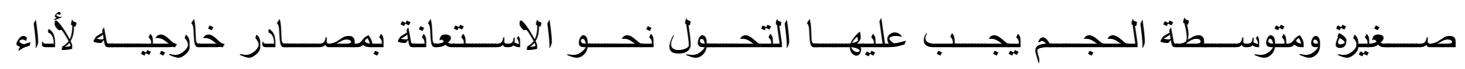


بعض المهـام (Lamminmaki， 2008; Kotabe\&Mol， 2009) وبشكل خاص المهـام المحاسبيـة (Kamyabi \& Devi, 2011b; Marriott \& Marriott, 2000). وبالتالـي فالاستعانة بمصادر خارجيه لأداء الأنثطة المحاسبية تمثل فرصسه لتلك الثركات للبقاء في المنافسة

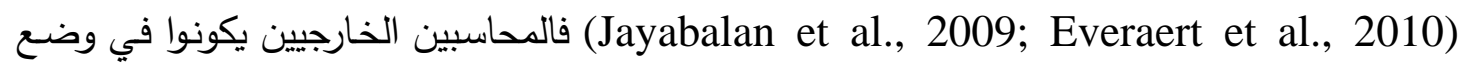

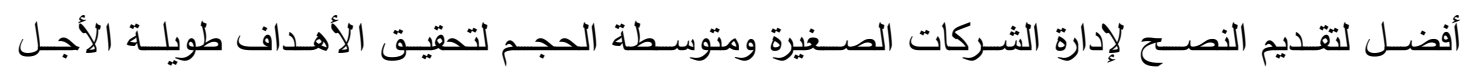

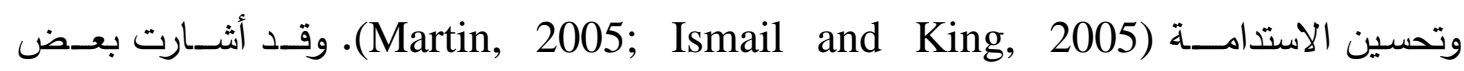
الدراسـات إلى أن الاستعانة بمصادر خارجيه لأداء العمل المحاسبي يرتبط بزيادة الطلب على المراجعة

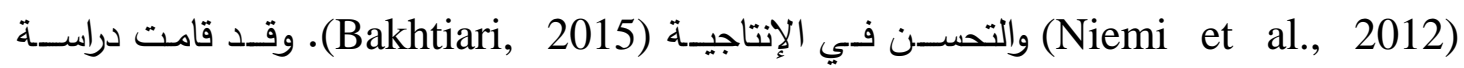
باستكثاف ما إذا كانت جودة التقرير المالي تختلف ما بين (Höglund \& Sundvik, 2016)

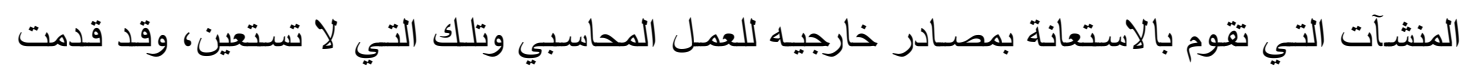
الدراسة أدلة عمليه على أن الاستعانة بمصادر خارجيه لأداء العمل المحاسبي مثل إعداد القوائم المالية يزيد من جودة التقرير.

ويمكن القول أن هناك بعض العوامل التي تئثر في قرار الاستعانة بالمصادر الخارجية ومنها قيود

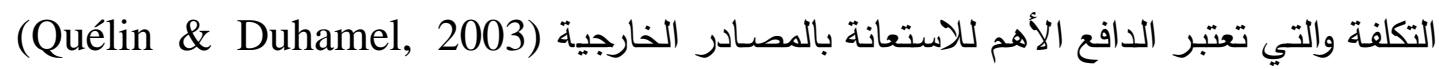

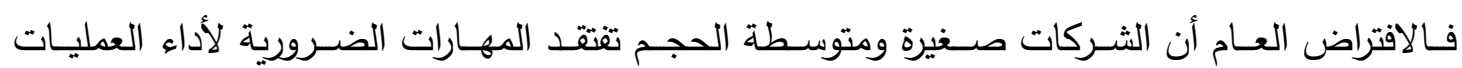

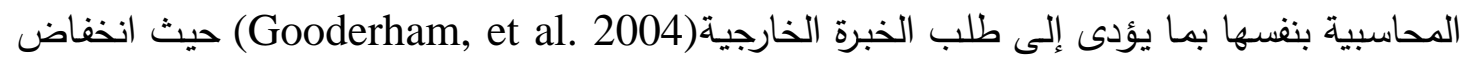

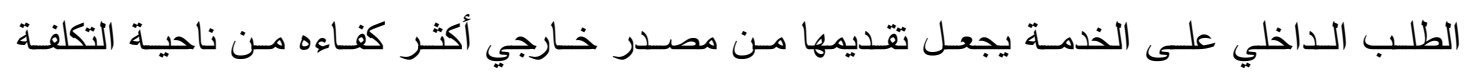

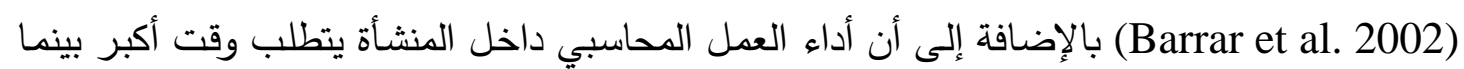

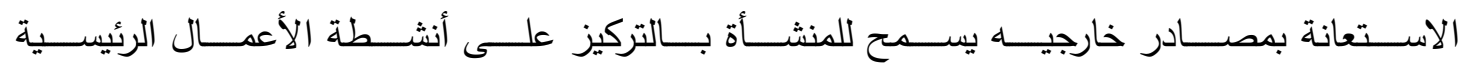
مقابل ذلك فهناك بعض الأسباب وراء (Gilley \& Rasheed, 2000; Quinn \& Hilmer, 1994)

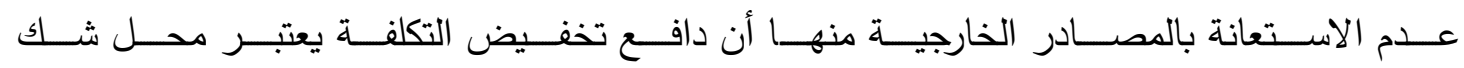

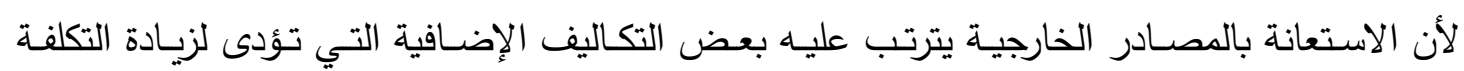
(Tomkins \& Green, 1988)

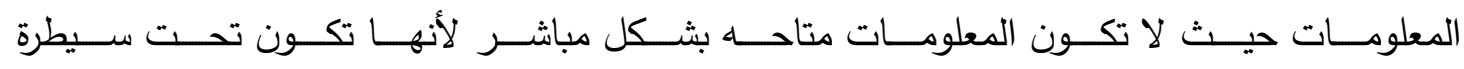

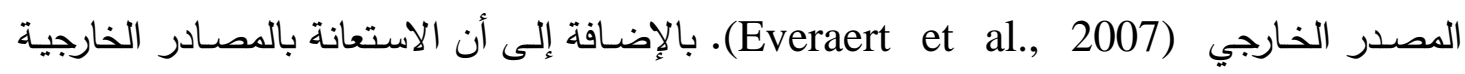

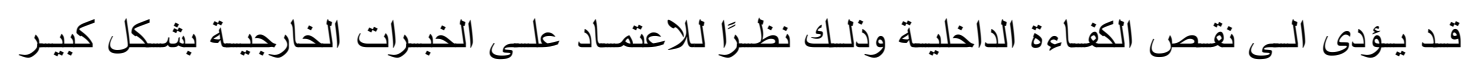
.(Gilley \&Rasheed, 2000; Quélin \& Duhamel, 2003) وقد طرحت دراسة (Höglund \& Sundvik, 2016) أن الاستعانة بالمصادر الخارجية لأداء

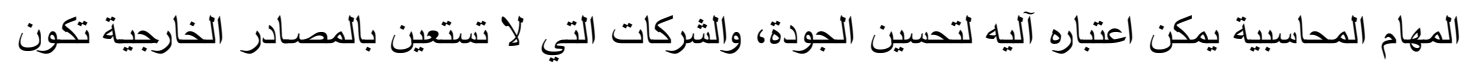

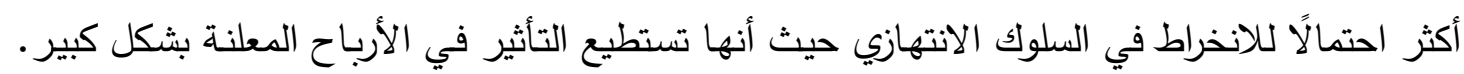

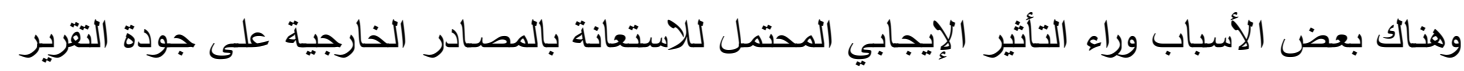

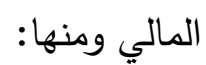


1- أن العديـــــــن الدراســات أوضــــت أن المراجـع كمقــدم خــارجي للخــدمات المحاسـبية يساهم في تحسين الكفاءة، فدراسـة (Nelson et al., 2002) وجدت أن المراجع كمراقب خارجي يسـاعد في اكتشـاف ومنـع ممارسـات إدارة الربح، ودراسـة \& Van Tendeloo ) وجدت أن جـودة المراجع تحـد مـن إدارة الـربح في سـياق الالتـزام الضريبي.

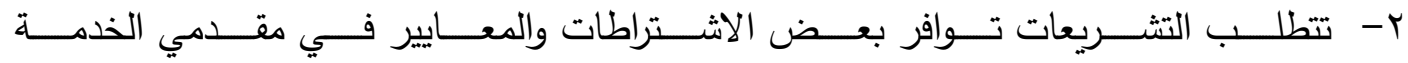
المحاسـبية ويمكـن النظـر لتــك المعـايير علــى أنهـا مصــدر إضــافي لتحسـين الجـودة - (Höglund \& Sundvik, 2016)

ب- حرص مقدمي الخدمة على سمعتهم يجعلهم أكثر حرصًا على رفع جودة الأعمال المحاسبية .(Weber, et al. 2008; Skinner \& Srinivasan 2012)

الآلية الثالثة: تتعلق بالمراجع حيث يمكن تحسين بيئة المعلومات بشكل غير مباشر عن طريق زيادة جودة المراجعة والتي تساهم بدورها في زيادة جودة المحاسبة. وتعتبر المراجعة من العوامل التي يمكن لهن

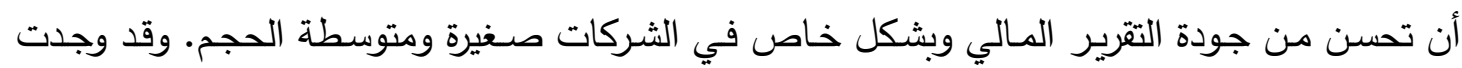

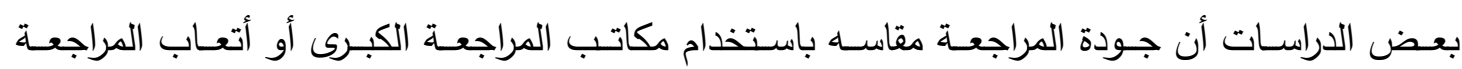

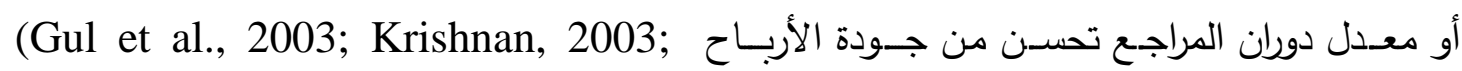
Myers et al., 2003; Srinidhi \& Gul, 2007; Caramanis \& Lennox, 2008) بعـض الدراسـات إلى أن جـودة المراجعـة تؤثر علىى تكلفـة الديـن Francis et al., 1999). Collis et al. 2004) وقد وجدت دراسة Fortin \& Pittman, 2007; Franco et al.,2011).

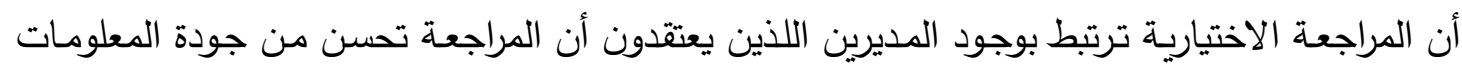

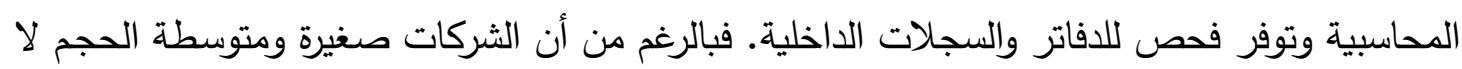

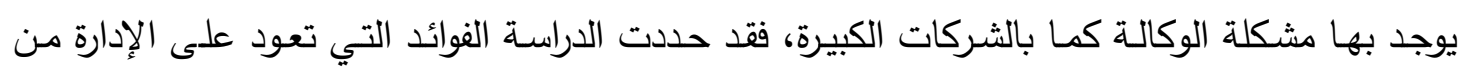

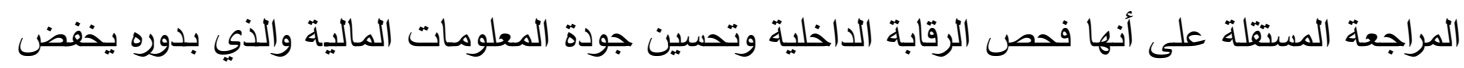
من خطر المعلومات. ففي الثركات الصغيرة، فإن الخطر المتلازم وخطر الرقابة الداخلية يكون كبير

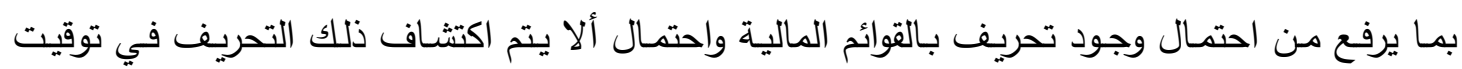
مناسب من خلال أساليب داخليه (Collis et al. 2004). وأشارت دراسة (Collis, 2003) إلى أن أن مشكلة عدم تماثل المعلومات والتي تبرر الطلب على خدمات المراجعة بشكل رئيسي يمكن أن تكون

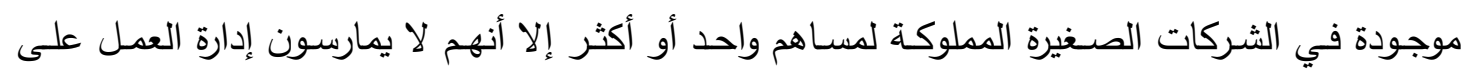

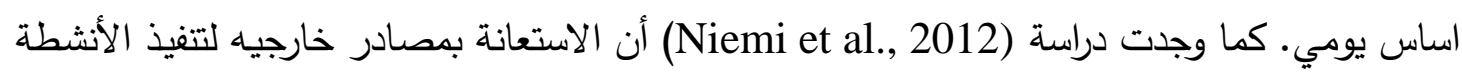
المحاسبية في تلك الثركات يخلق الحاجة للرقابة على عدم تماثل المعلومات ما بين الثركة والمحاسب الخارجي وهو ما يؤدى لزيادة احتمال اللجوء الى المراجعة المستقلة.

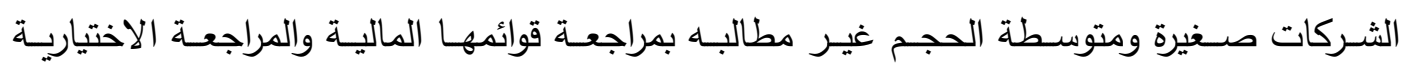
(Kim et al., 2011; Minnis, 2011; تعتبر أحد مؤشرات جودة التقرير المالي لتلك الشركات 
Huguet \& Gandia, 2014) وقدمت نتائج دراسة (Lennox \& Pittman, 2011) عن الشركات

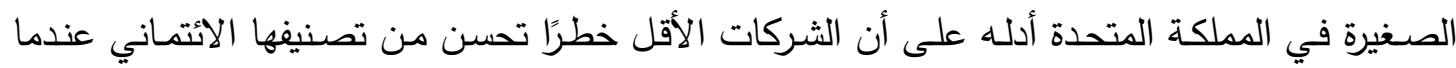

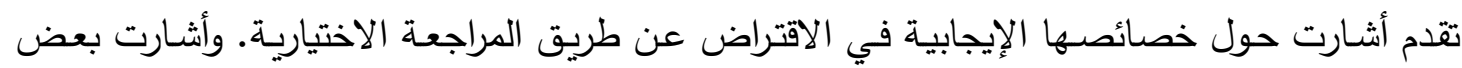

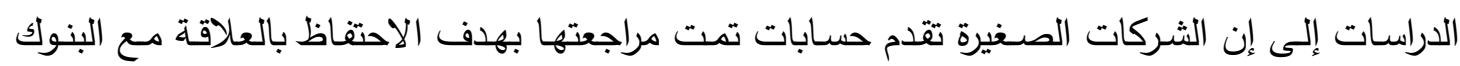

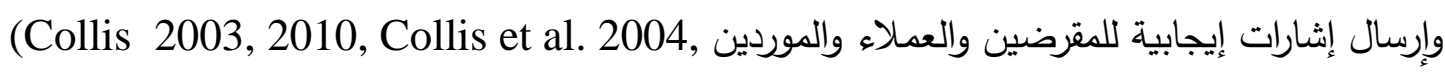
(Boone et al. 2010) وقان اختيار مكاتب المراجعة Collis \& Jarvis 2000).

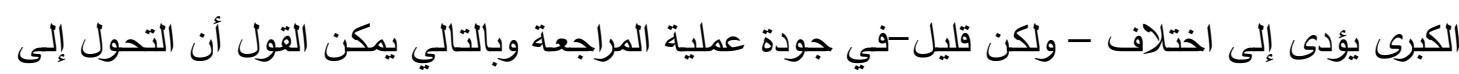
استخدام أحد مكاتب المراجعة الكبرى يعتبر قرار لتحسين بيئة المعلومات.

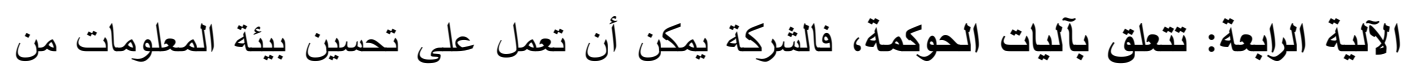

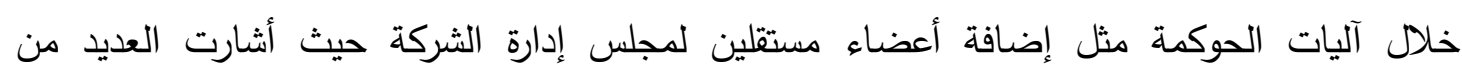

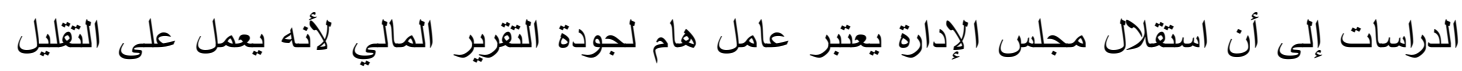

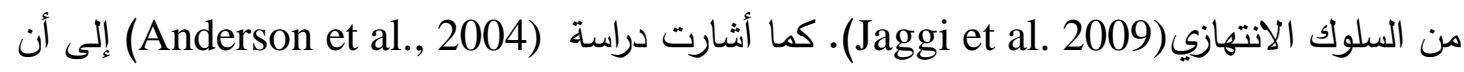
استقلال مجلس الإدارة يرتبط بالتخفيض في تكلفة التمويل بالدين. ويمكن القول أن الأعضاء المستقلين

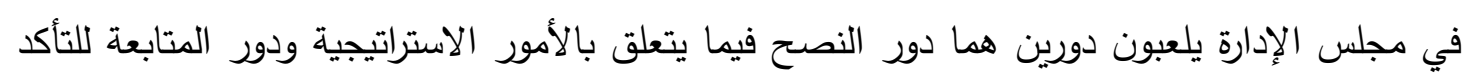

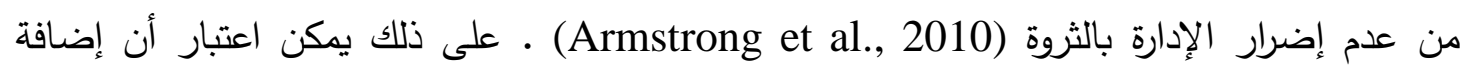
أعضاء مستقلين في مجلس الإدارة على أنه دحاوله لتحسين بيئة المعلومات.

\section{r- الاراسات السابقة وتطوير فروض البحث:}

\section{ب-1 محددات التحسن في بيئة المعلومات:}

النسبة الأكبر من الثركات صغيرة ومتوسطة الحجم تكون مقيده ماليًا حيث لا يمكنها الوصول للتمويل

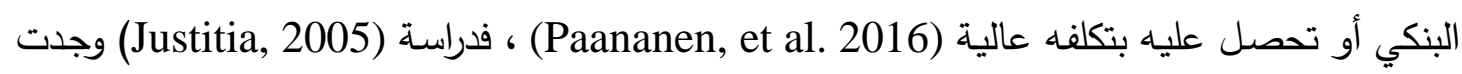

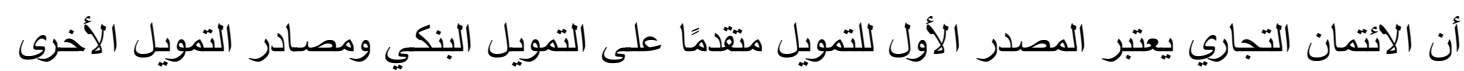

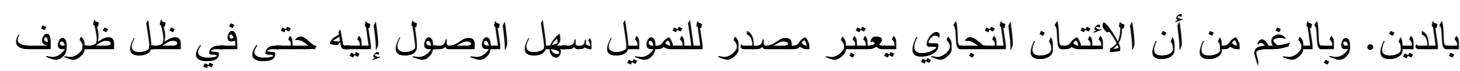

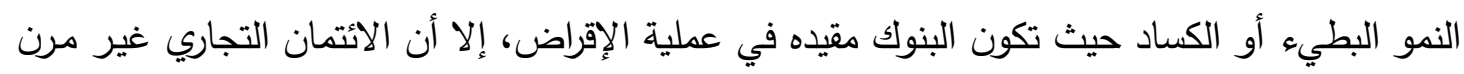

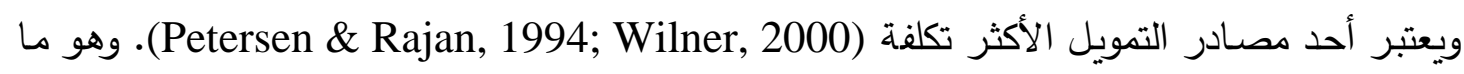
يمثل مشكله أكبر للشركات صغيرة ومتوسطة الحجم التي تعتمد بشكل أكبر على الايتمـان كمصدر التهر

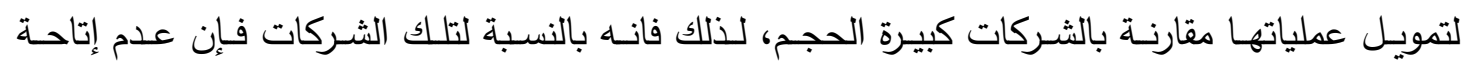
الاقتراض طويل الأجل وتكلفة الاقتراض تعتبر من الأمور الهامة جدا

.Moro et al.,2014)

ومن الأسباب الرئيسية لتحفظ البنوك في إقراض الشركات هو انخفاض جودة المعلومات المتاحة

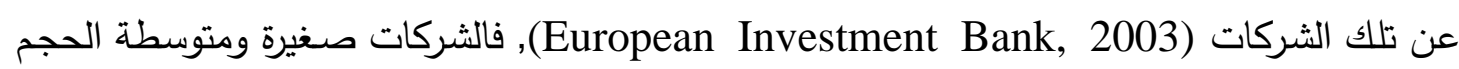


غالبَّا لا تسـتطيع توصـيل مراكزهـا الماليـة بطريقـهـ يمكـن الاعتمــاد عليهـا ولـديها صـعوبات أكثر (European Commission, 2003; مي بنـاء سمعة جيـدة تعكـس ارتفـاع الجـودة لديهـا European Investment Bank, 2003) البنوك تطلب توافر معلومات عالية الجودة كشرط أساسي لمنح القروض للشركات صـغيرة ومتوسطة الحجم، فإنه يمكن توقع أن تلك الثركات التي تواجه زيـادة في الديون قصيرة الأجل تكون أكثر احتمالاً

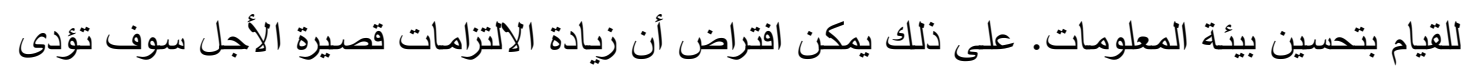
إلى التحسن في بيئة المعلومات وهو ما يتطلب اختبار الفرض التالي:

الفـرض الأول: هــاك ارتبـاط إيجـابي بـين الزيــادة في الالكزامـات قصـيرة الاجـل والتحسـن في بيئة

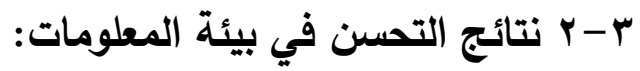

منفعة التقرير المالي غالبًا ما يتم تتاولها في سياق منفعة المعلومات للمستخدمين في اتخاذ القرار (Brüggemann et al. 2013). حيث يلعب التقرير المالي دورين الأول: توفير معلومات للمستثمرين الحـاليين والمـرتقبين تسـاعدهم في توقـع التـدفقات النقديـة المستقبلية وقيمـة الثـركة، والثـاني: تمكين

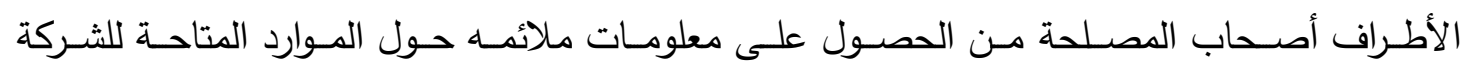
(He et al., 2012; Brüggemann et al.,2013) والأطراف أصحاب المصلحة مثل اتفاقات الاقتراض وتعهدات التمويل تعتمد على المعلومات المحاسبية (Brüggemann et al., 2013). وهناك نقاش مستمر حول ما إذا كان التقرير المالي يستطيع القيام بالدورين في نفس الوقت (Brüggemann et al., 2013; Bradshaw et al., 2014), فالبعض يطرح أن التقريـر عـالي الجودة والذي يـوفر معلومـات مفيدة للمستثمرين يجب أيضـا أن يكـون مفيد للأطراف أصحاب المصلحة الأخرين مثل المقرضين. بينما يطرح أخرين أن التقرير عالي الجودة يعتبر

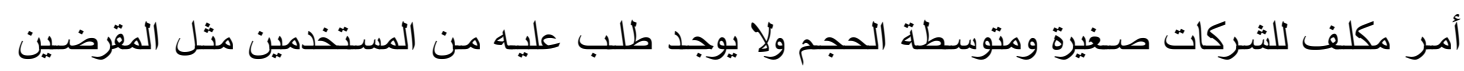
(Bradshaw et al., 2014, Berger \& Udell, 2002) ويمكن القول أن التحسن في بيئة المعلومات يمكن الثركات من التحول إلى الاعتماد بشكل أكبر

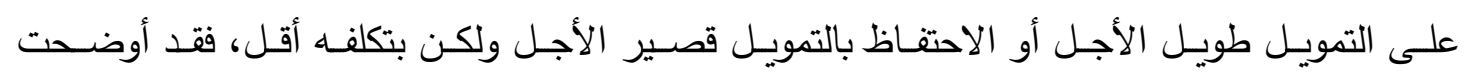

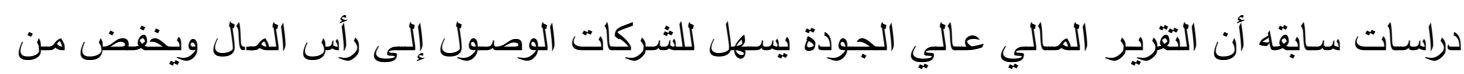
تكلفة الدين (Diamond and Verrecchia 1991; Leuz \& Verrecchia 2000; Easley \& ف'Hara 2004; Francis et al., 2005; Chen et al., 2011; Hope et al., 2013). فان تحول الشركات صغيرة ومتوسطة الحجم إلى تطبيق معايير (IFRS) يمكن المقرضين من الاستفادة من بيئة المعلومات المحسنة بما يقود إلى الوصول بشكل أكبر للديون طويلة الأجل وتخفيض في تكلفة

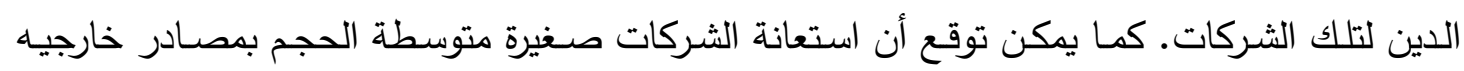
لتنفيذ العمل المحاسبي واستخدامها لمكاتب المراجعة الكبرى سوف يفيد المقرضين من خلادل تحسين 
التقارير المحاسبية مما يؤدى إلى سهولة الوصول للديون طويلة الأجل وتخفيض تكلفة الدين. كذلك فإن مجلس الإدارة هو المسئول عن الإشراف على عملية التقرير المالي ويوفر الأعضـاء المستقلين متابعـه أكثر كفـاءة لأنشطة الثـركة، على ذلك يمكن توقع أن إضـافة أعضـاء مستقلين لمجلس الإدارة يفيد المقرضين من خلال تحسن بيئة المعلومات بما يؤثر على سهولة الوصول لرأس المال وتخفيض تكلفة

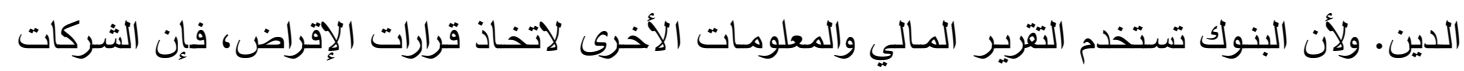

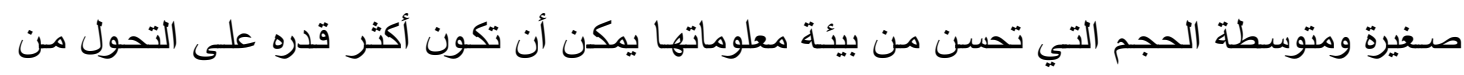
الديون قصيرة الأجل المكلفة والائتمان التجاري إلى الديون طويلة الأجل مع تخفيض فئن في تكلفة الدين. وبالتالي يمكن اختبار الفرضين التاليين: الفرض الثاني: التحسن في بيئة المعلومات يؤدى الى الزيادة في الدين طويل الأجل الفرض الثالث: التحسن في بيئة المعلومات يؤدى الى تخفيض في تكلفة الدين

\section{ع - تصميم الاراسة ومنهج البحث: \\ ع - 1 مجتمع وعينة الدراسة :}

يتمثل مجتمع الدراسة في جميع الثركات الصغيرة والمتوسطة المقيدة ببورصة النيل المصرية والبالغ

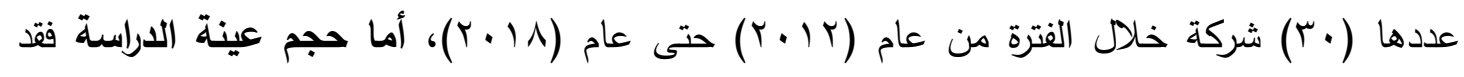
تحديده بعد التحقق من توافر الثروط التالية: أن يكون هناك تداول فعلي على أسهم الثركات، وأن تتوافر التقارير المالية بانتظام خلال فترة الدراسة التي مدتها (V) سنوات، أن تتوافر بها البيانات الكافية

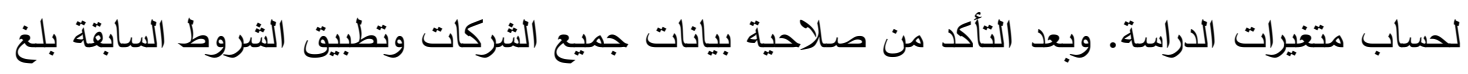

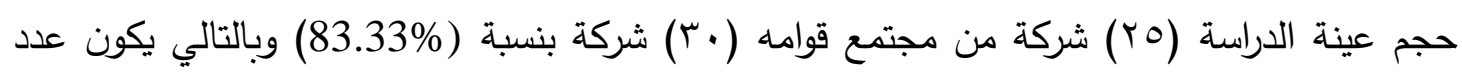
المشاهدات (175) مشاهدة.

ع - r مصادر جمع البيانات :

تم جمع بيانات الدراسة التطبيقية من خلال القوائم المالية السنوية للشركات الصغيرة والمتوسطة المقيدة ببورصة النيل المصرية وما تتضمنه من إيضاحات متممة لها، وكذلك تقرير مراقب الحسابات لتحديد نوع الرأي بالتقرير، وتم الحصول على هذه المعلومات من شركة مصر لنشر المعلومات بالإضافة إلى بعض المواقع الإكترونية مثل موقع بورصة النيل

المصرية nilex.egyptse.com، وكذلك المواقع الرسمية الإكترونية لبعض الشركات عينة الدراسة. ع - ع نماذج الاراسة:

لاختبار فروض الدراسة تم استخدام نماذج الانحدار بأسلوب البيانات المجمعة panel data وهناك

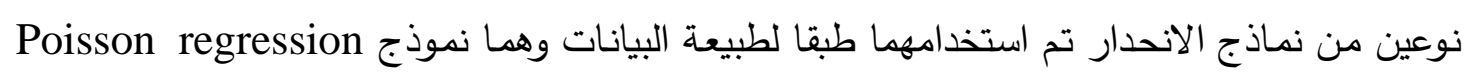
لاختبار الفرض الأول حيث أن المتغير التابع هو التحسن في بيئة المعلومـات يعتمد على بيانات

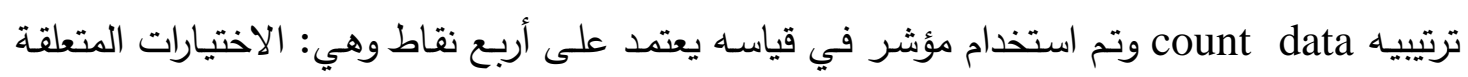


بالمعـيير المحاسبية والهـراجعين واستقلال مجلس الإدارة والاستعانة بمصـادر خارجيـه لتتفيذ المهام المحاسبية، و يتراوح المؤشر من (·) إلى (ع) اعتمادًا على:

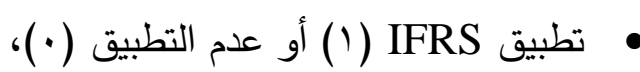

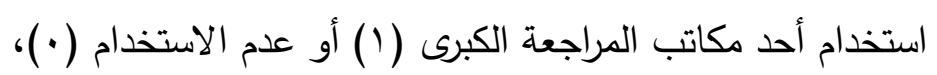

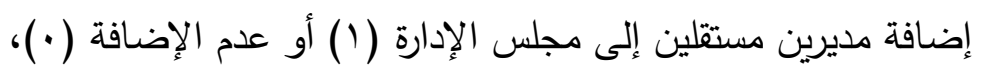

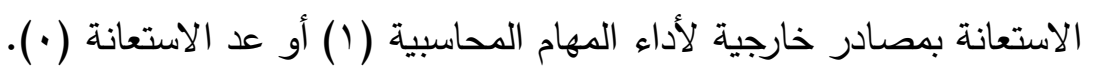
ونموذج linear regression لاختبار الفرضين الثاني والثالث. ولاختبار الفرض الأول المتعلق

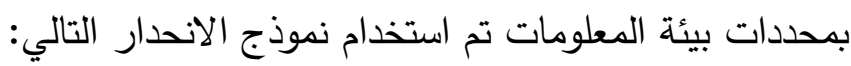

$\mathrm{IE}_{\mathrm{it}}=\beta_{0}+\beta_{1} \Delta \mathrm{Cl}_{\mathrm{it}-1}+\beta_{2} \Delta \mathrm{LD}_{\mathrm{it}-1}+\beta_{3} \mathrm{SG}_{\mathrm{it}-1}+\beta_{4} \Delta \mathrm{SIZE}_{\mathrm{it}-1}+\beta_{5} \Delta \mathrm{PRO}_{\mathrm{it}-1}+\beta_{6}$ AGE $\mathrm{it}-1+\beta_{7} \mathrm{CFO}_{\text {it }-1}+\beta_{8} \mathrm{TA}_{\mathrm{it}-1}+\varepsilon$

$$
\begin{aligned}
& \text { حيث أن: } \\
& \text { المتغير التابع: } \\
& \text { التحسن في بيئة المعلومات طبقا للمؤشر المستخدم. IE } \\
& \text { المتغير المستقل: } \\
& \text { ACL } \\
& \text { متغيرات الرقابة: }
\end{aligned}
$$

تتضمن هذه المتغيرات العوامل الأخرى التي قد تؤثر في التحسن في بيئة المعلومات بالإضافة إلى متغير

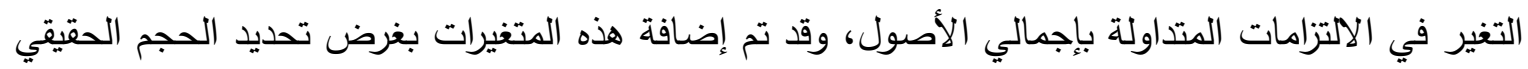

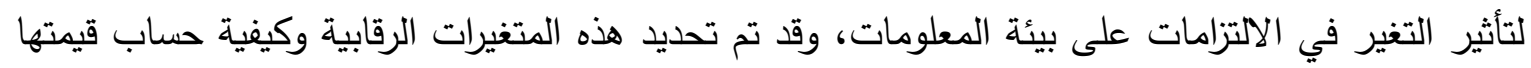
في ضوء الدراسات السابقة (Bradshow et al.,2014;Moro et al.,2014;Hope etal.,2013) وكذلك في ضوء مدى توافر البيانات اللازمة لحسابها ضمن التقارير المالية للشركات الدصرية محل الدراسة ومن

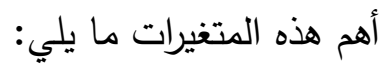

$$
\begin{aligned}
& \text { LLD } \\
& \text { SG }
\end{aligned}
$$

ASIZE

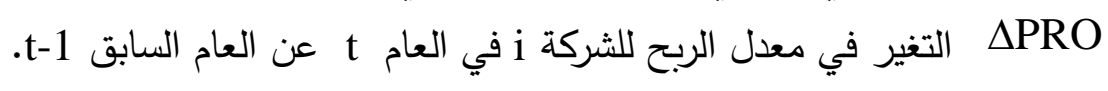

AGE

$$
\text { موضوع التحليل. }
$$

CFO

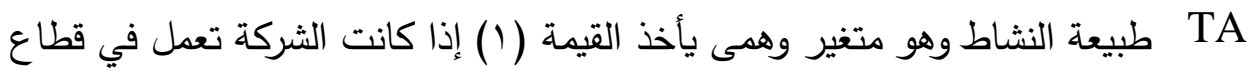

$$
\text { صناعي والقيمة (·) بخلاف ذلك. }
$$




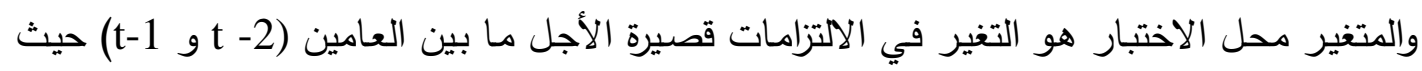

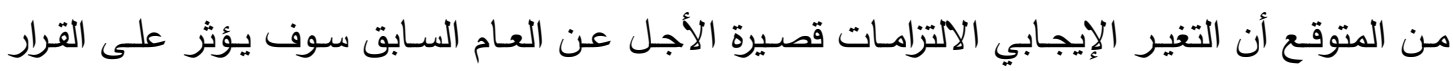

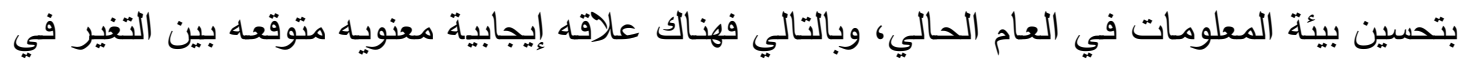
الالتزامات طويلة الأجل وجودة بيئة المعلومات. وتم استخدام المتغيرات المستقلة متعلقة بالعام السابق

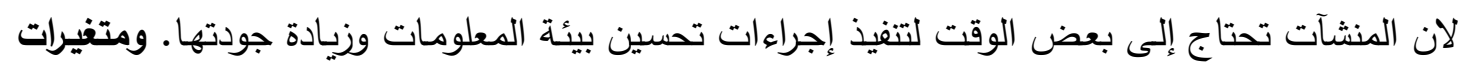

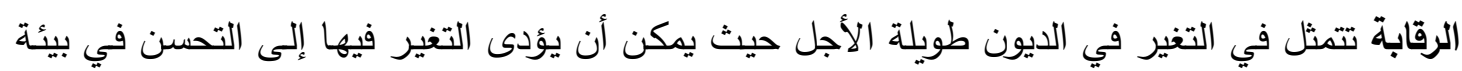

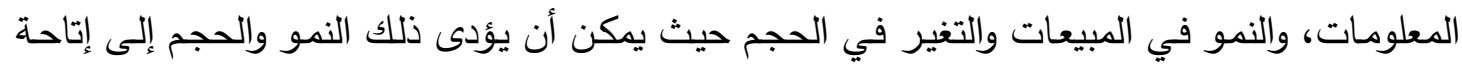

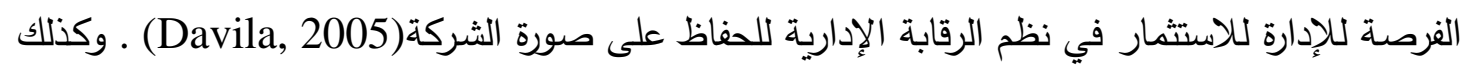

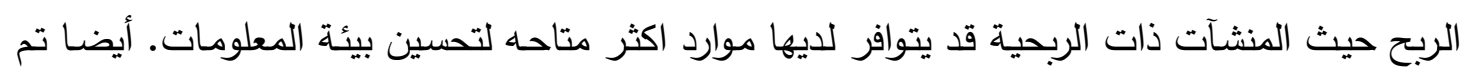

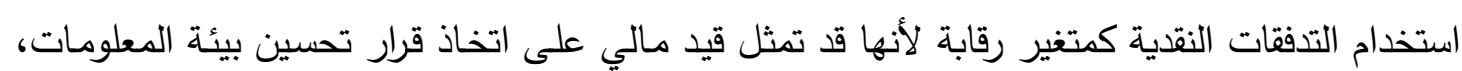
بالإضافة إلى متغير يعكس طبيعة نثاط الثركة.

ولاختبار الفرض الثاني المتعلق بتأثير التحسن في بيئة المعلومات على التمويل بالديون طويلة

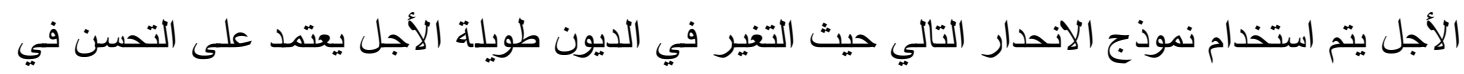
بيئة المعلومات مع استخدام بعض متغيرات الرقابة:

$\Delta \mathrm{LD}_{\mathrm{it}}=\beta_{0}+\beta_{1} \mathrm{IE}_{\mathrm{it}-1}+\beta_{2} \Delta \mathrm{CL}_{\mathrm{it}-1}+\beta_{3} \mathrm{SG}_{\mathrm{it}-1}+\beta_{4} \Delta \mathrm{SIZE}_{\mathrm{it}-1}+\beta_{5} \Delta \mathrm{PRO}_{\mathrm{it}-1}+\beta_{6}$ $\mathrm{AGE}_{\mathrm{it}-1}+\beta_{7} \mathrm{CFO}_{\mathrm{it}-1}+\beta_{8} \mathrm{TA}_{\mathrm{it}-1}+\beta_{9} \Delta \mathrm{IA}_{\mathrm{it}-1}+\varepsilon$

SIA

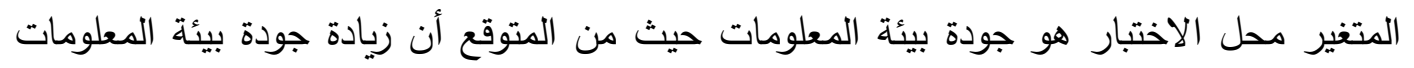

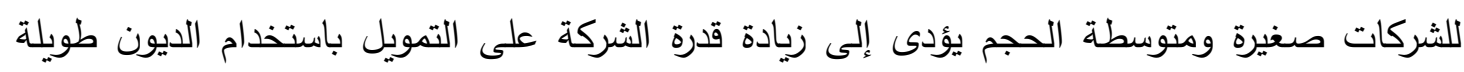

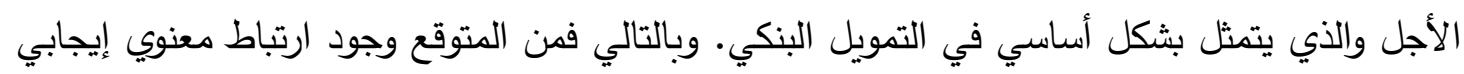

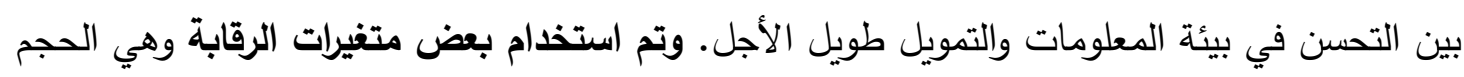

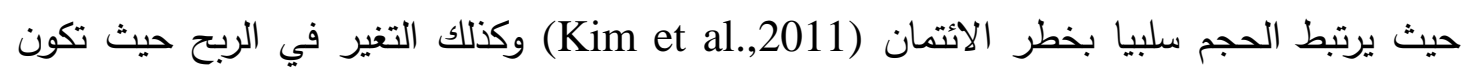

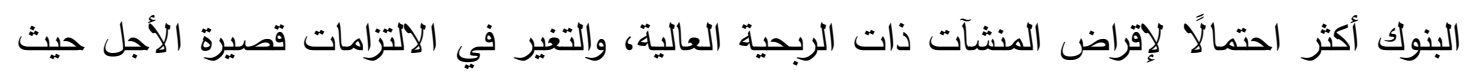

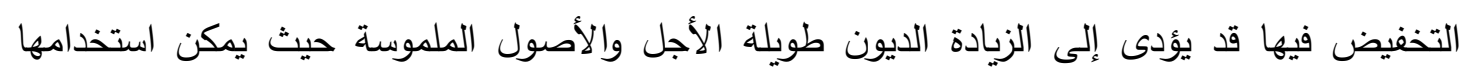
كضمان (Kim et al., 2011) .بالإضافة الى نمو المبيعات والتدفقات النقدية و طبيعة النشاط.

ولاختبار الفرض الثالث المتعلق بتأثير التحسن في بيئة المعلومات على معدل الفائدة يتم استخدام

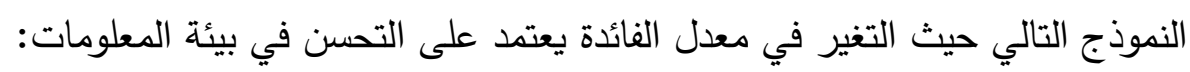

$\Delta \mathrm{INT}_{\mathrm{it}}=\beta_{0}+\beta_{1} \mathrm{IE}_{\mathrm{it}-1}+\beta_{2} \Delta \mathrm{LD}_{\mathrm{it}-1}+\beta_{2} \Delta \mathrm{CL}_{\mathrm{it}-1}+\beta_{3} \mathrm{SG}_{\mathrm{it}-1}+\beta_{4} \Delta \mathrm{SIZE}_{\mathrm{it}-1}+$ $\beta_{5} \Delta \mathrm{PRO}_{\mathrm{it}-1}+\beta_{6} \mathrm{AGE}_{\mathrm{it}-1}+\beta_{7} \mathrm{OP}_{\mathrm{it}-1}+\beta_{8} \mathrm{TA}_{\mathrm{it}-1}+\beta_{8} \Delta \mathrm{IA}_{\mathrm{it}-1}+\varepsilon$ 
التغير في معدل الفوائد محسوبا بقيمة مصروف الفوائد موزون بقيمة الالتزامات.

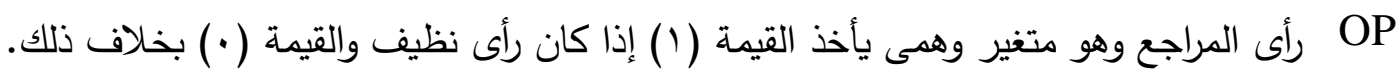

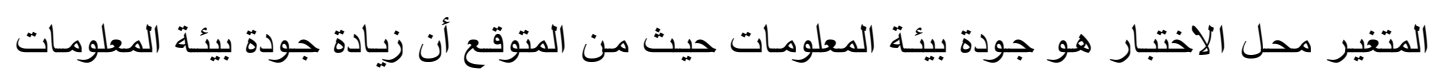

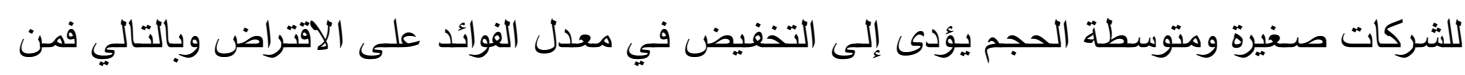

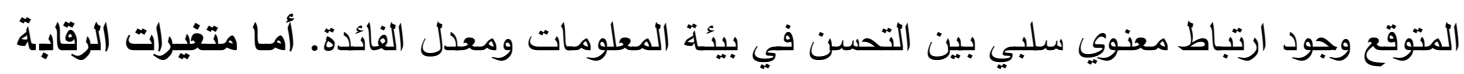

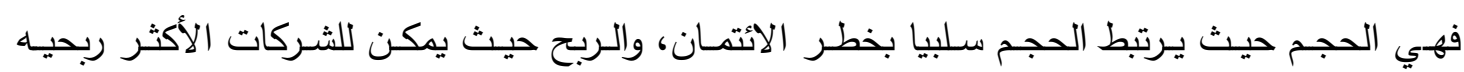

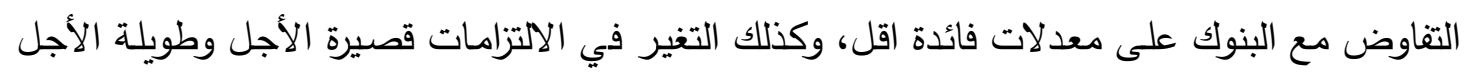
والأصول الملموسة. بالإضافة إلى نمو المبيعات ورأى المراجع وطبيعة النشاط. ه- نتائج الاراسة التطبيقية: ه-

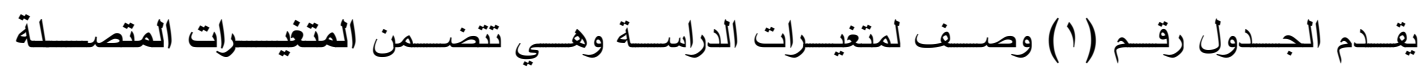
Continuous Variables

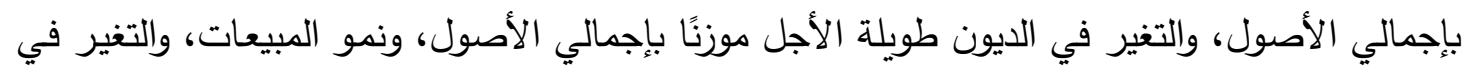
إجمالي الأصول، والتغير في معدل الربح، وعمر الثركة، والتدفقات النقدية التشغيلية.

جدول رقم (1): نتائج الإحصاء الوصفي ولني

\begin{tabular}{||c|c|c|c|c|c||}
\hline \multicolumn{7}{|l|}{ Part 1: continuous variables } \\
Var. & N. & Min. & Max. & Mean & Std. Dev. \\
\hline IE & 175 & 1 & 4 & 3.034286 & 0.8963344 \\
\hline$\Delta$ CL & 175 & 0.17 & 4.25 & 0.3616469 & 0.3302385 \\
\hline$\Delta$ LD & 175 & 0.071 & 2.77 & 0.3264971 & 0.2278908 \\
\hline SG & 175 & -0.167 & 0.487 & 0.2815829 & 0.1851466 \\
\hline$\Delta$ SIZE & 175 & 0.081 & 0.411 & 0.2359886 & 0.0985098 \\
\hline$\Delta$ PRO & 175 & -0.174 & 0.475 & 0.2602343 & 0.1578023 \\
\hline AGE & 175 & 9 & 26 & 17.32 & 4.127341 \\
\hline C FO & 175 & -0.164 & 0.396 & 0.24492 & 0.1299432 \\
\hline$\Delta$ IA & 175 & 0.211 & 0.784 & 0.4596514 & 0.149625 \\
\hline$\Delta$ INT & 175 & 0.034 & 0.297 & 0.1706914 & 0.0796405 \\
\hline Part 2: dummy variables & \multicolumn{7}{c|}{} \\
\hline Var. & \multicolumn{7}{|c|}{112} & $64 \%$ & 63 & $36 \%$ \\
\hline TA & 75 & $43 \%$ & 100 & $57 \%$ \\
\hline OP
\end{tabular}

يتضح من الجدول السابق ارتفاع متوسط مؤشر التحسن في بيئة المعلومات خلال فترة الدراسة

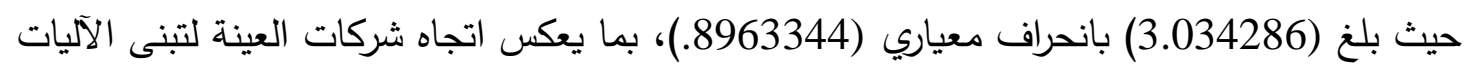

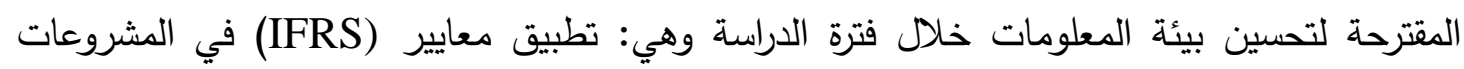
الصغيرة والمتوسط الحجم واعتمادها في بعض الأحيان على فروع فكات فراتب المراجعة الكبرى واهتمامها 
بوجود أعضاء مستقلين في مجلس الإدارة بالإضافة إلى استعانة هذه المشروعات بمصادر خارجية لأداء

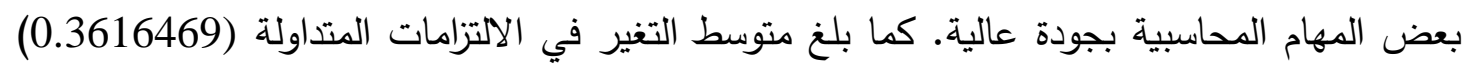

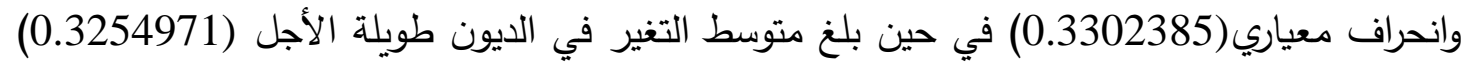
بانحراف معياري (2278908.).

وبالنسبة لنمو المبيعات فهناك تحسن بسيط في مستوى النمو حيث بلغت أكبر نسبة له (48.7\%) في حين أقل نسبة له (16.7\%-) بمتوسط حسابي (0.2815829) وانحراف معياري (0.2359) (0.1851466)،

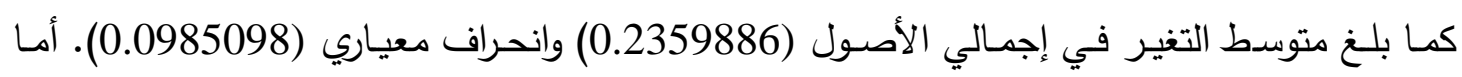

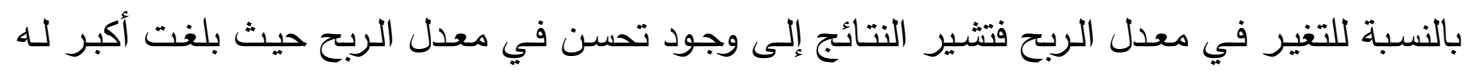

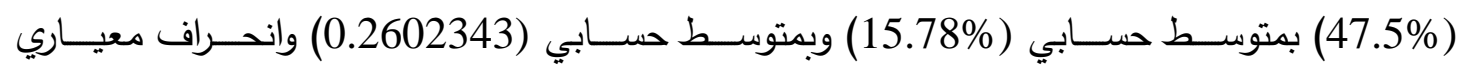

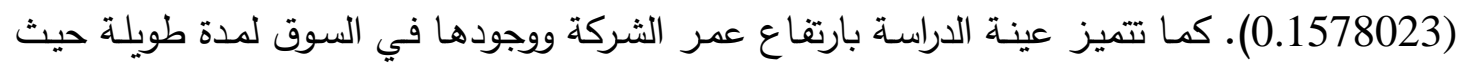

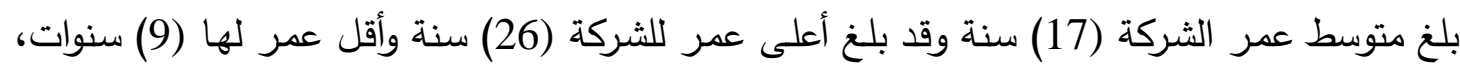

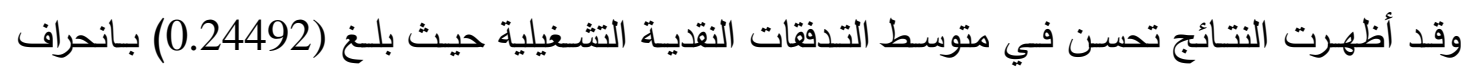

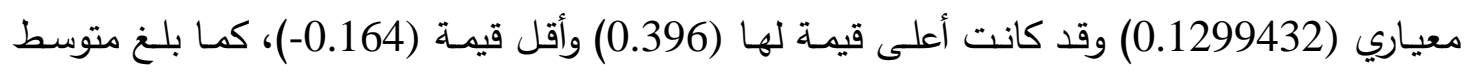

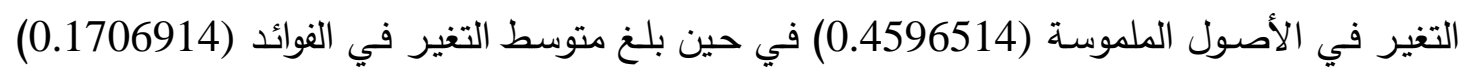
بانحراف معياري (0.0796405).

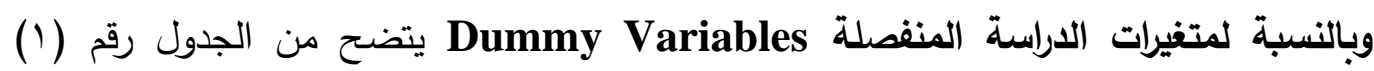

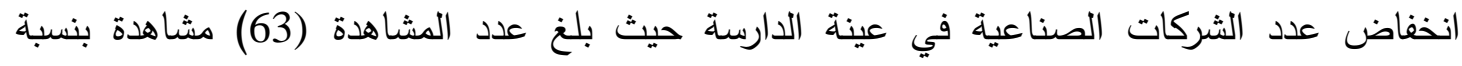

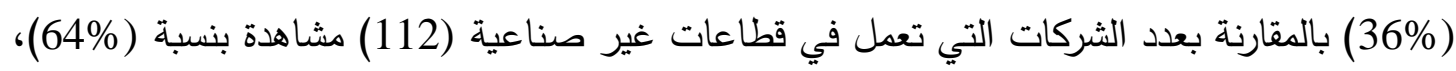

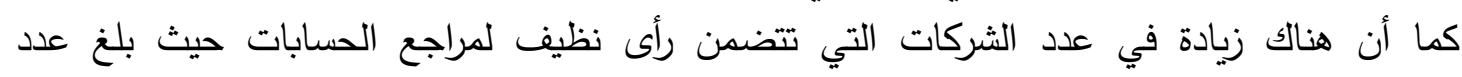

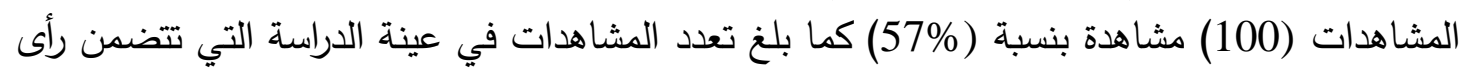
أخر (غير نظيف)(75) مشاهدة بنسبة (43\%).

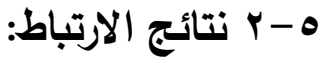

لتحليل علاقة الارتباط الفردية بين التحسن في بيئة المعلومات ومتغيرات الاطبات الدراسة يعرض الجدول رقم

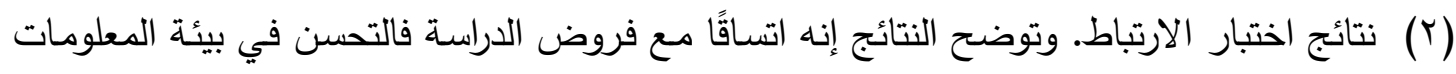

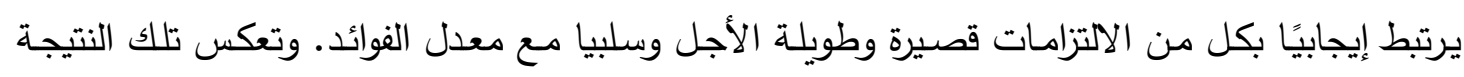

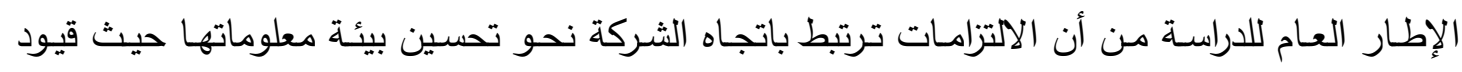

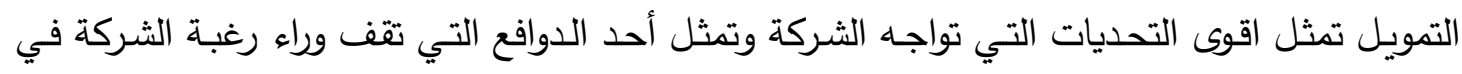

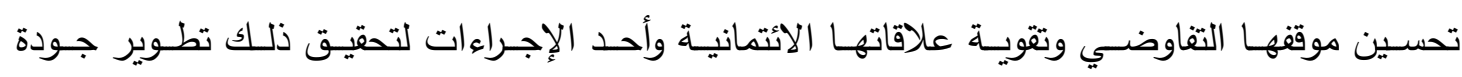

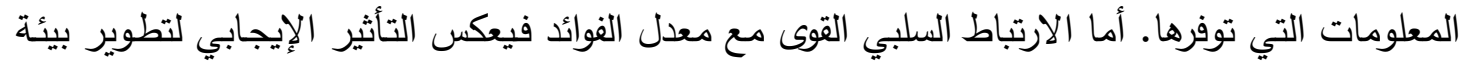

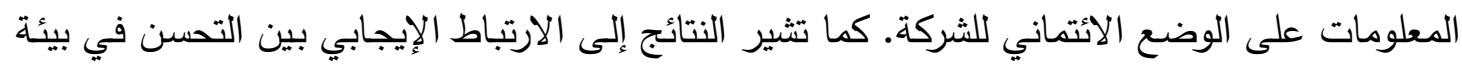

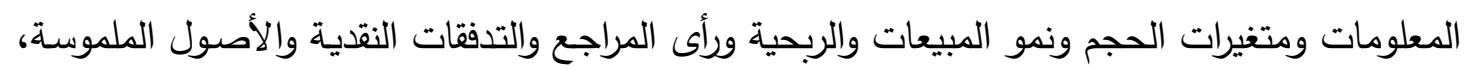
بينما لا يرتبط طبيعة النثاط بتطوير بيئة المعلومات. 
جدول رقم (ץ): نتائج اختبار الارتباط بين التحسن في بيئة المعلومات ومتغيرات الدراسة

\begin{tabular}{|c|c|c|c|c|c|c|c|c|c|c|c|}
\hline & IE & $\Delta \mathrm{CL}$ & $\Delta \mathrm{LD}$ & $\Delta \mathrm{INT}$ & SG & & & OP & & TA & \\
\hline IE & 1 & $0.321^{* * *}$ & $0.452^{* *}$ & $-0.837^{* *}$ & $0.703^{* *}$ & $0.770^{\text {*** }}$ & $0.671^{* *}$ & $0.693^{* *}$ & $0.675^{\text {** }}$ & $0-.055$ & $0.720^{*}$ \\
\hline & & .000 & .000 & .000 & .000 & .000 & .000 & .000 & .000 & .466 & \\
\hline
\end{tabular}

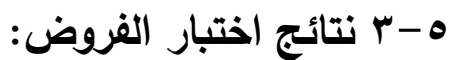

لاختبار الفرض الأول المتعلق بما إذا كان التغير في الالتزامات قصيرة الأجل يؤثر على قرار الشركة

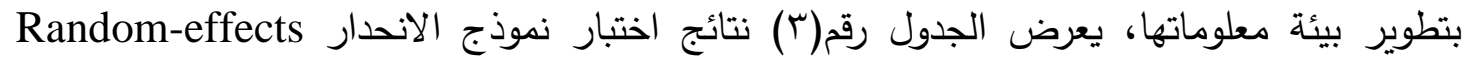
Poisson regression النتائج وجود ارتباط معنوي إيجابي بين التغير في الالتزامات قصيرة الأجل وجودة بيئة المعلومات

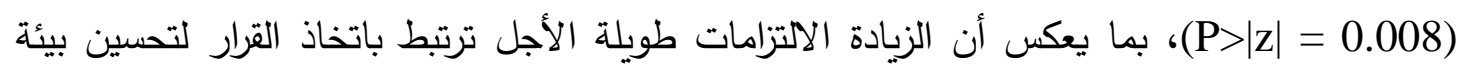
المعلومات وبالتالي صحة الفرض الأول من فروض النان الدراسة. جدول رقم (ץ): نتائج اختبار نموذج الاتحار لأثر الاتتزامات قصيرة الأجل على بيئة المطومات

\begin{tabular}{|c|c|c|c|c|c|c|}
\hline & Coef. & Std. Err. & $z$ & $P>|z|$ & [95\% Con] & Interval] \\
\hline$\Delta \mathrm{CL}$ & .0195115 & .1389872 & 4.14 & 0.008 & -.2528985 & 2919215 \\
\hline$\Delta \mathrm{LD}$ & .0540191 & .2037486 & 1.27 & 0.079 & -.3453207 & .4533589 \\
\hline SG & .4030057 & .6567103 & 0.61 & 0.539 & -.8841228 & 1.690134 \\
\hline$\Delta$ SIZE & 1.310576 & .8271638 & 3.58 & 0.011 & -.3106354 & 2.931787 \\
\hline$\triangle \mathrm{PRO}$ & .0265157 & .6740471 & 0.04 & 0.969 & -1.294592 & 1.347624 \\
\hline AGE & .0057796 & .0122787 & 1.47 & 0.063 & -.0182863 & .0298454 \\
\hline $\mathrm{CFO}$ & .2918072 & .7532745 & 1.39 & 0.069 & -1.184584 & 1.768198 \\
\hline TA & -.0443721 & .0966142 & -0.46 & 0.646 & -.2337325 & .1449883 \\
\hline Cons. & .4701031 & 2052365 & 2.29 & 0.022 & .067847 & .8723593 \\
\hline Number of obs. & \multicolumn{6}{|l|}{175} \\
\hline Number of groups & \multicolumn{6}{|l|}{7} \\
\hline Wald chi2(8) & \multicolumn{6}{|l|}{28.64} \\
\hline Prob > chi2 & \multicolumn{6}{|l|}{0.0004} \\
\hline Log likelihood & \multirow{2}{*}{\multicolumn{6}{|c|}{$\begin{array}{l}-268.09896 \\
\text { Random-effects Poisson regression }\end{array}$}} \\
\hline Model & & & & & & \\
\hline
\end{tabular}

ولاختبـار الفـرض الثـاني المتعلق بمـا إذا كـان التحسن في بيئـة معلومـات الثـــكات الصــيرة

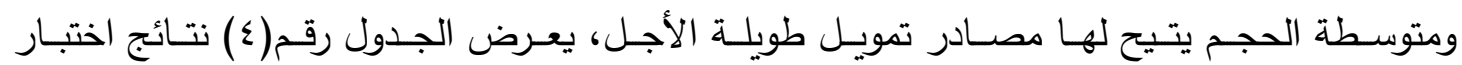
نموذج الانحـدار Random-effects GLS regression حيث توضح النتائـج معنويـة النــوذج وتوضــح النتائسج وجـود ارتبـاط معنوي إيجابـي بيـن التحسن في بيئة (Prob> chi2 = 0.000).

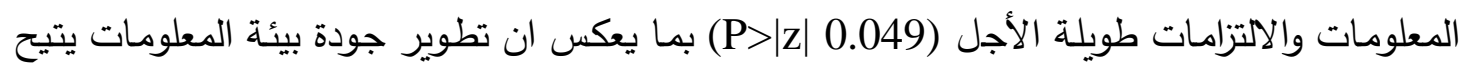

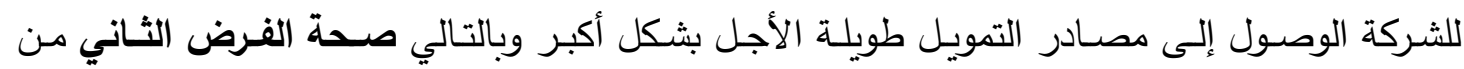




\begin{tabular}{|c|c|c|c|c|c|c|}
\hline & Coef. & Std. Err. & $\mathrm{Z}$ & $\mathrm{P}>|\mathrm{z}|$ & [95\% Conf & Interval] \\
\hline $\mathrm{IE}$ & .1149321 & .0280161 & 2.53 & 0.049 & -.1399785 & .1698427 \\
\hline$\Delta \mathrm{CL}$ & .0029129 & .050714 & .66 & 0.195 & -.0964848 & .1023105 \\
\hline SG & .0821972 & .2002525 & 0.41 & 0.681 & -.3102905 & .474685 \\
\hline$\triangle \mathrm{SIZE}$ & .5402673 & .3232666 & 1.67 & 0.095 & -.0933236 & 1.173858 \\
\hline$\triangle \mathrm{PRO}$ & .1971052 & .2089718 & 3.94 & 0.034 & -.2124719 & .6066824 \\
\hline AGE & .0026048 & .0042151 & 0.62 & 0.537 & -.0056565 & .0108662 \\
\hline $\mathrm{CFO}$ & -.0984976 & .2307 & -.43 & 0.166 & -.5506612 & .3536661 \\
\hline TA & .0194686 & .0334119 & 0.58 & 0.560 & -.0460175 & .0849548 \\
\hline$\Delta \mathrm{IA}$ & .1999012 & .1929414 & 1.04 & 0.300 & -.178257 & .5780595 \\
\hline Cons. & -.0416856 & .078508 & -1.53 & 0.059 & -.1955584 & .1121872 \\
\hline Number of obs. & \multicolumn{6}{|l|}{175} \\
\hline Number of groups & \multicolumn{6}{|l|}{7} \\
\hline Wald chi2(9) & \multicolumn{6}{|l|}{70.38} \\
\hline Prob > chi 2 & \multicolumn{6}{|l|}{0.0000} \\
\hline R-sq: overall & \multicolumn{6}{|c|}{0.2990} \\
\hline Model & \multicolumn{6}{|c|}{ Random-effects GLS regression } \\
\hline
\end{tabular}

ولاختبار الفرض الثالث المتعلق بما إذا كان التحسن في بيئة معلومات الشركات صغيرة ومتوسطة الحجم يؤدى إلى التخفيض في تكلفة التمويل في شكل مصروف الفوائد، يعرض الجدول رقم(0) نتائج اختبار نموذج الانحدار Random-effects GLS regression حيث توضـح النتائج معنويـة النموذج (Prob> chi2 = 0.000) وتظهر النتائج ارتباط معنوي سلبي بين التحسن في بيئة المعلومات

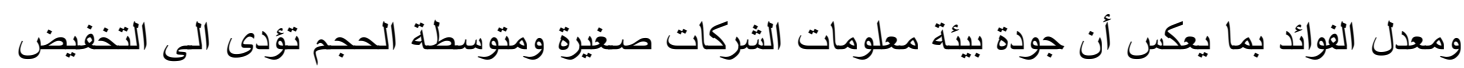

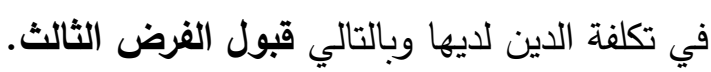
جدول رقم (•): نتائج اختبار الاتحدار لأثر التحسن في المعلومات على تكلفة الايون

\begin{tabular}{|c|c|c|c|c|c|c|}
\hline & Coef. & Std. Err. & $\mathrm{z}$ & $\mathrm{P}>|\mathrm{z}|$ & \multicolumn{2}{|c|}{ [95\% Conf. Interval] } \\
\hline IE & -0.2303217 & .0043212 & -1.12 & 0.019 & -0.3387912 & -0.1218522 \\
\hline$\Delta \mathrm{LD}$ & .0080811 & .0120091 & 1.67 & 0.050 & -.0154563 & .0316186 \\
\hline$\Delta \mathrm{CL}$ & .0202632 & .0077115 & 2.63 & 0.009 & .0051489 & .0353775 \\
\hline SG & .0541074 & .0309777 & 1.75 & 0.081 & -.0066078 & .1148226 \\
\hline$\triangle \mathrm{SIZE}$ & .3028716 & .0481655 & 6.29 & 0.000 & .208469 & .3972743 \\
\hline$\triangle \mathrm{PRO}$ & -.0060543 & .031803 & -0.19 & 0.849 & -.068387 & .0562784 \\
\hline $\mathrm{OP}$ & .0029023 & .0072867 & 0.40 & 0.690 & -.0113793 & .0171839 \\
\hline $\mathrm{AGE}$ & .0731251 & .0348121 & 2.10 & 0.036 & .0048947 & .1413554 \\
\hline TA & .0102593 & .0049216 & 2.08 & 0.037 & .0006132 & .0199055 \\
\hline$\Delta \mathrm{IA}$ & .0084254 & .0076401 & 2.09 & 0.036 & -.0149915 & .0318423 \\
\hline Cons. & -.0396924 & .0096538 & -4.11 & 0.000 & -.0586134 & -.0207714 \\
\hline Number of obs. & \multicolumn{6}{|l|}{175} \\
\hline Number of groups & \multicolumn{6}{|l|}{7} \\
\hline Wald chi2(10) & \multicolumn{6}{|l|}{1038.96} \\
\hline Prob > chi2 & \multicolumn{6}{|l|}{0.0000} \\
\hline R-sq: overall & \multicolumn{6}{|l|}{0.8630} \\
\hline Model & \multicolumn{6}{|c|}{ Random-effects GLS regression } \\
\hline
\end{tabular}


تسـاهم الثركات الصغيرة والمتوسطة الحجم بشكل محوري في التطور الاقتصـادي وذلك من حيث خلق الوظـائف والنـاتج المحلى الإجمالي والمسـاعدة في استقرار الاقتصـاد القومي في البلدان الناشئة (Ale-Ebrahim et al., 2010). الا أن تلك الثركات تتعامل مع تعقيدات متزايدة وفثل الأداء في الدول الناشئة وذلك لنقص الموارد (Kamyabi \& Devi, 2011c), كما أن الشركات الصغيرة تكون أقل كفاءه من الثركات الكبيرة في تخصيص واستغلال الموارد (Gooderham et al., 2004). في

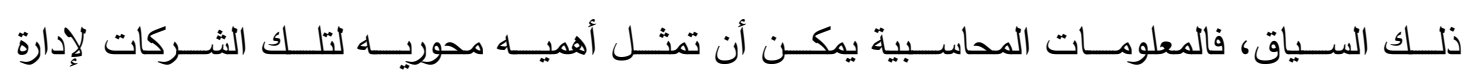

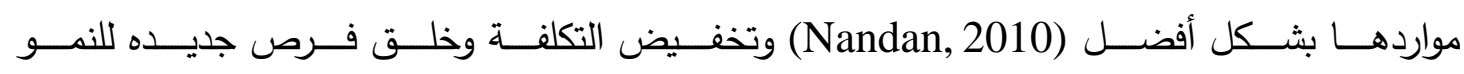

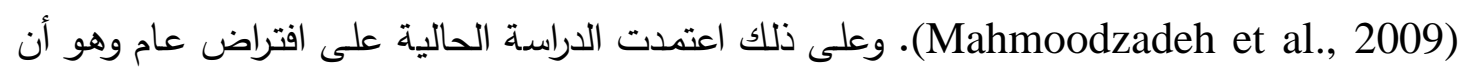
تطوير بيئة معلومات الثركات صغيرة ومتوسطة الحجم يمثل أهمية كبيره لنجاح واستمرار تلك الثركات التي وبدورها تمثل أهمية كبيره للاقتصاد المصري في الوقت الراهن حيث يساهم ذلك النمط من الشركات بشكل جوهري في مواجهة مشاكل أساسية في الاقتصاد المصري مثل البطالة وتحقيق التتمية بمفهومها

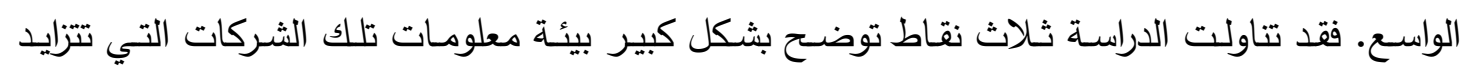
أهميتهـا، الأولى: العوامـل التي ترتبط بتحسين تلك المنشـآت لبيئـة المعلومـات (المحددات)، الثانيـة: التصرفات التي تقوم بها لتحسين بيئة المعلومات، الثالثة: النتائج التي يمكن أن تعود عليها من تحسين

واعتمـدت الدراسـة في تحليل محددات ونتائج التحسن في بيئة المعلومـات على افتراض أن أهم

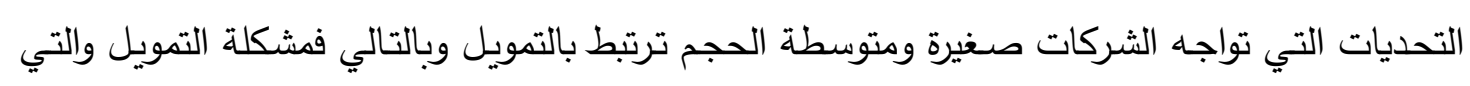

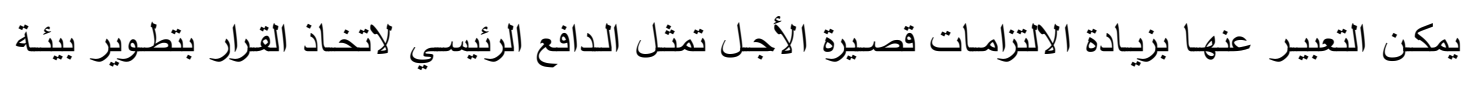

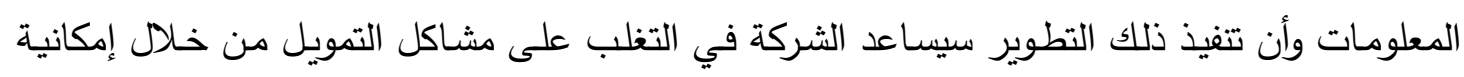

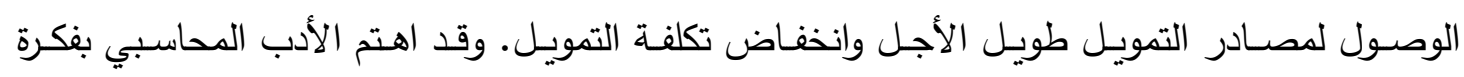
الارتباط بين الديون والتقرير المالي، فقد اهتمت بعض الدراسات بتأثير معدل الرافعة وعقود الدين على ولى ولى جودة التقرير المالي وأشارت بعض النتائج إلى أن معدل الدين إلى حقوق الملكية المرتفع يرتبط سلبيًا

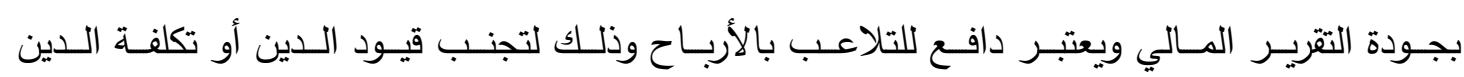
المرتفعة.(Ball et al., 2008; Armstrong et al., 2010; Ghosh and Moon, 2010) كما أن المقرضين يستخدمون معدلات الدين في عقود الدين وبالتالي فالشركات تميل للتلاعب بالأرباح لتحسين معدلاتها وتخفيض تكلفة الدين.

وفيما يتعلق بمحددات التحسن في بيئة المعلومات، أظهرت نتائج الدراسـة الحالية التأثير المعنوي للتغير الإيجابي الالتزامات قصيرة الأجل على التوجه نحو تحسين بيئة معلومات الثركة، وبالتالي فاتجاه الالتزامات قصيرة الأجل نحو الزيادة يحفز الشركة على تحسين بيئة معلوماتها. وتتسق تلك النتيجة مع التح نتائج دراسة (Zuelch and Burghardt, 2010) والتي أشارت إلى أنه فيما يتعلق بالثركات صغيرة 
ومتوسطة الحجم فإن تقييم الائمان الذي يجريه البنك يعتبر دافع للتغيير النظام الدحاسبي. وقد أشارت

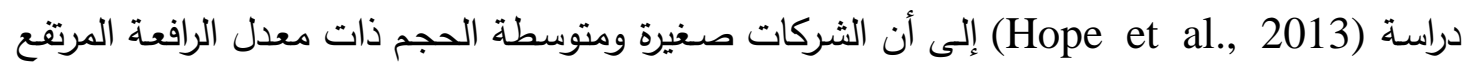

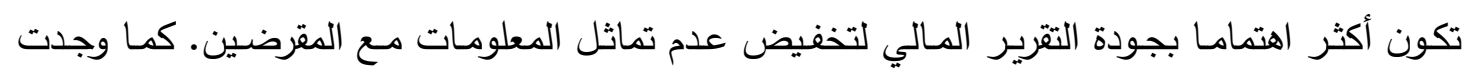
دراسة (Van Caneghem \& Van Campenhout, 2012) أن الشركات صغيرة ومتوسطة الحجم

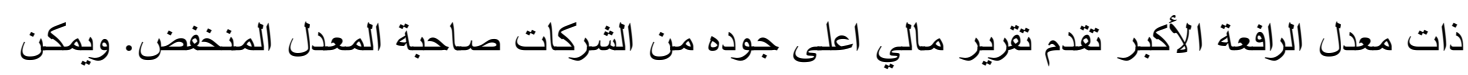

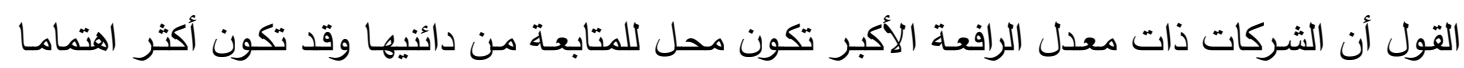

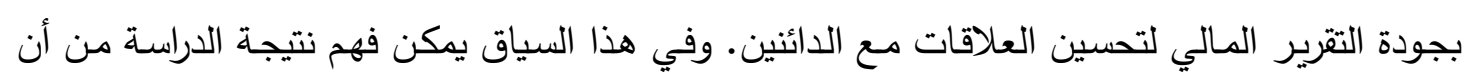

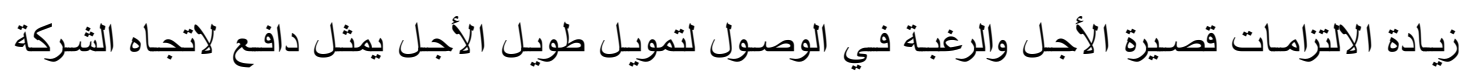
للاهتمام ببيئة معلوماتها.

كما توضح النتائج جدول رقم(r) أن التغير في الالتزامات طويلة الاجل ترتبط ارتباط معنوي إيجابي

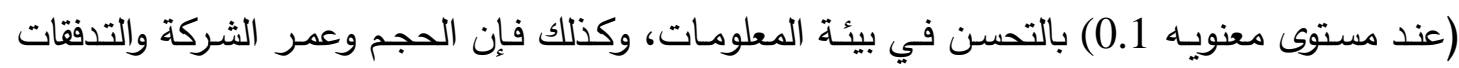

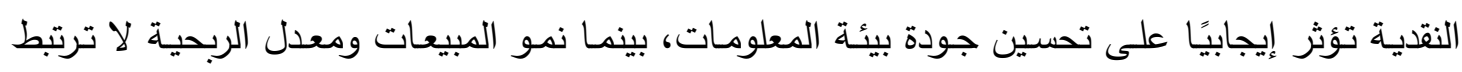
بقرار تحسين جودة بيئة المعلومات. وتوضح تلك الحئن النتائج أن التغير في حجم الثركة هو الأكثر تأثيرًا

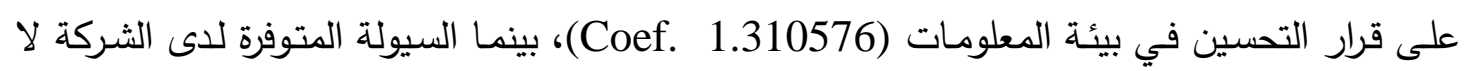

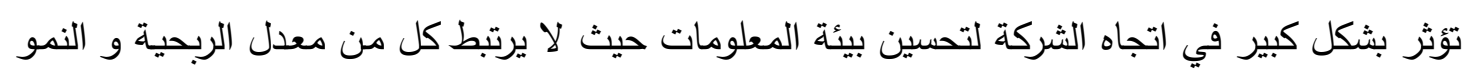

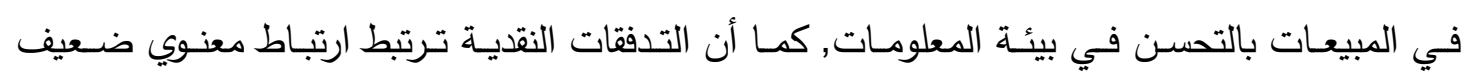

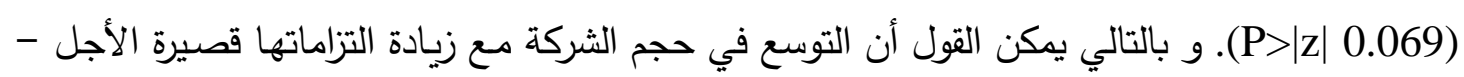

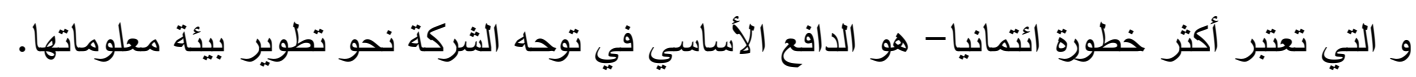

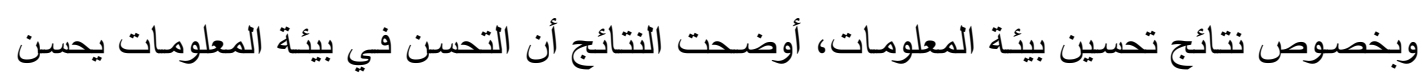

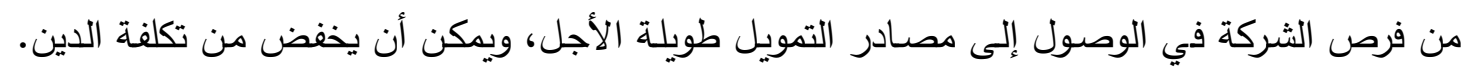

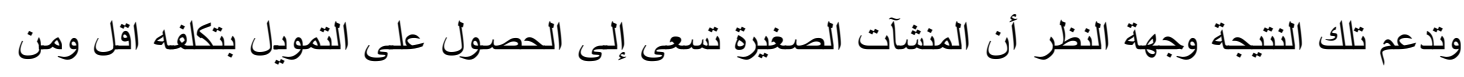

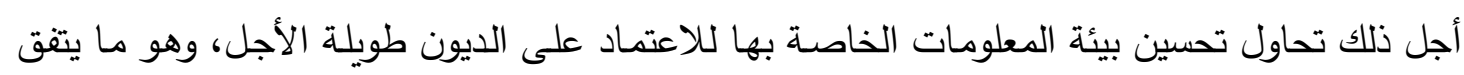

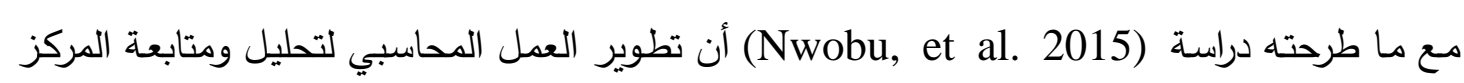

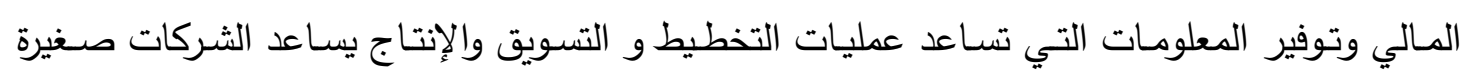

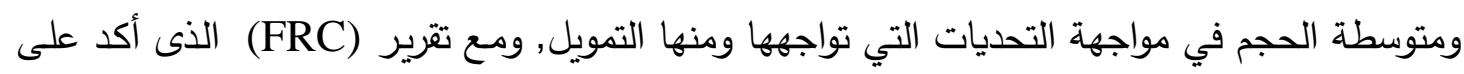

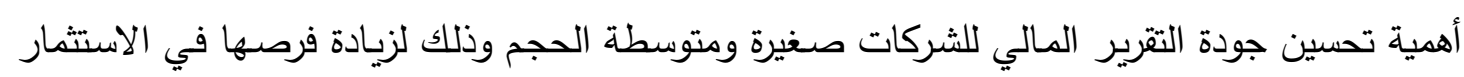

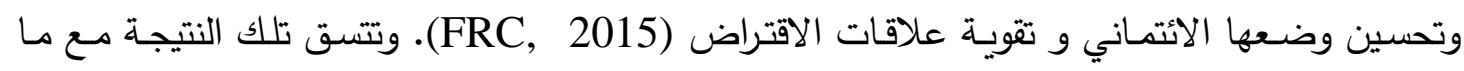

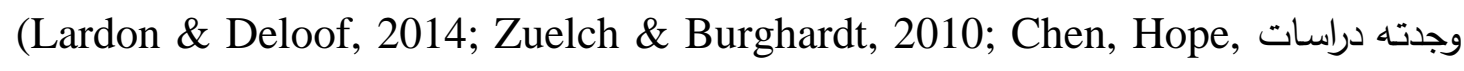
أن أن جودة القوائم المالية والثفافية

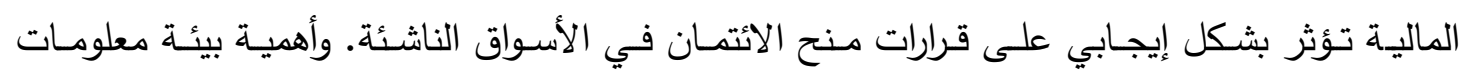

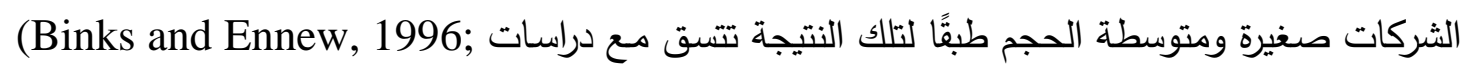
Carvalho \& Abramovay, 2004; Ortiz-Molina and Penas, 2008; Degryse, de 
Goeij and Kappert, 2012)

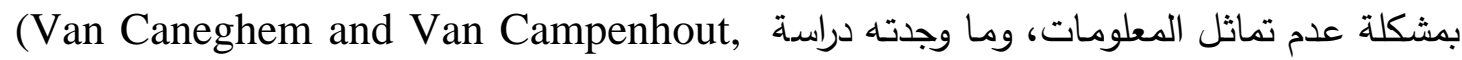
(2012 من أن كميـة و جودة المعلومـات المحاسبية ترتبط بهيكل راس المـال في الثركات صـئيرة

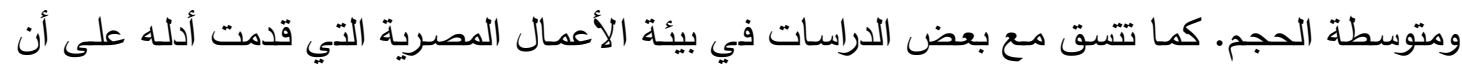
بعض الآليات المقترحة لتحسين بيئة المعلومات تنعكس بثكل إيجابي على تلك الثركات، فدراسـة

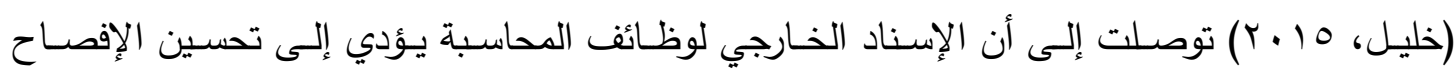

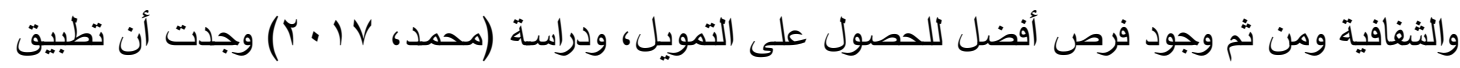
معيار التقرير المالي للمشروعات الصغيرة (IFRS For SMEs) يساهم في زيادة جودة الإفصـاح

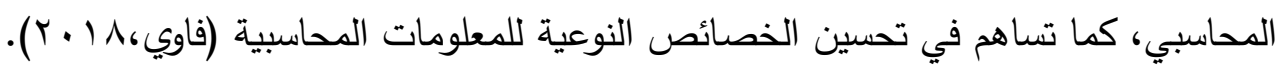

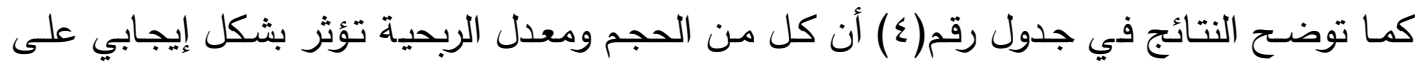

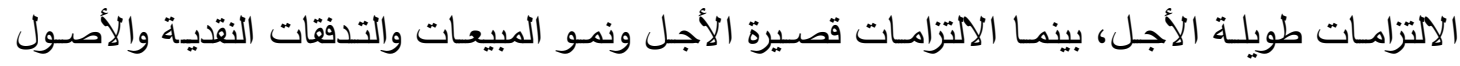

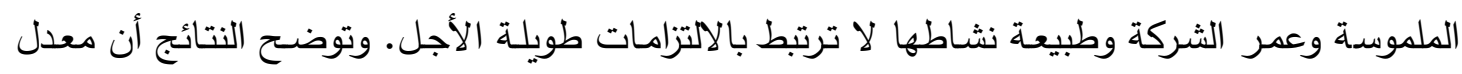

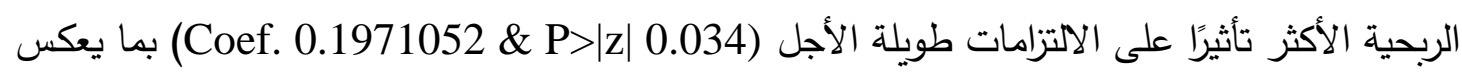

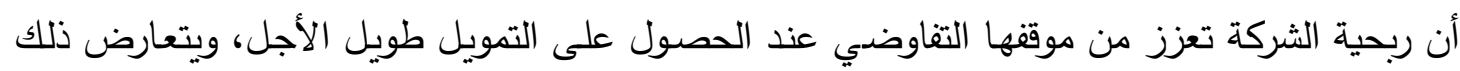

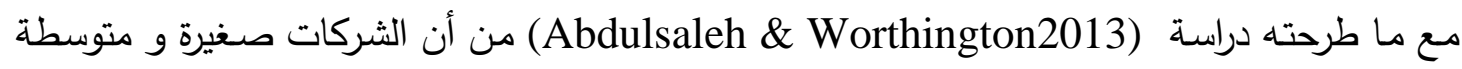
الحجم الأكثر ربحيه تحتجز جزء من أرباحها وبالتالي تكون الحاجه إلى مصادر التمويل الأخرى أقل.

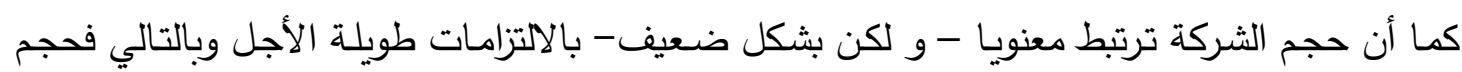

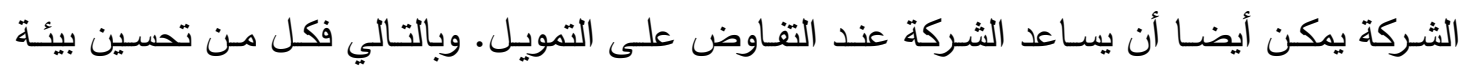

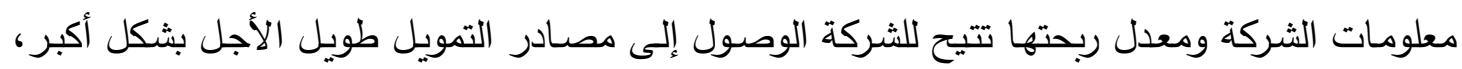
كما أن حجم الشركة يساعد في ذلك إلى حد مات التهات وبشكل عام فقد قدمت نتائج الدراسة أدله عمليه حول العوامل التي تقف وراء تطوير وزيادة جودة بيئة

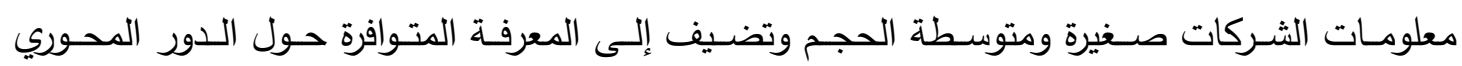

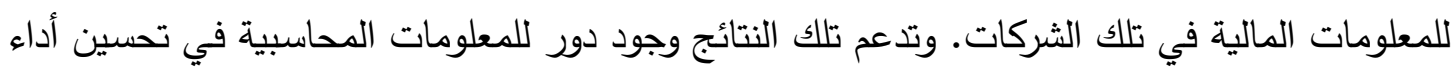

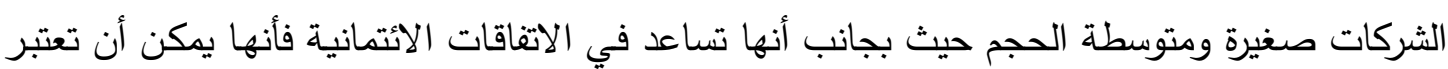
كأداة للرقابة وتساعد في الأمور الضريبية.

צ- 1 - النتائج والتوصيات وحدود الدراسة والتوجهات البحثية المستقبلية: 1- تمثل الزيادة في الالتزامات قصيرة الأجل دافع للثركات صغيرة ومتوسطة الحجم لتحسين بيئة معلوماتها. 
ץ- يؤدى التحسن في جودة بيئة المعلومات للشركات صغيرة ومتوسطة الحجم الى زيادة قدرة الشركة على التمويل باستخدام الديون طويلة الأجل. ب- يؤدى التحسن في جودة بيئة المعلومات للشركات صغيرة ومتوسطة الحجم الى الانخفاض في تكلفة الدين في شكل معدل الفوائد.

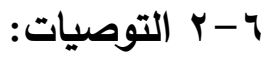

على ضوء النتائج التي تم التوصل إليها في كل من الدراسة النظرية والتطبيقية يوصي الباحثان بما يلي: 1- زيادة وعي الشركات بأهمية تطبيق الممارسات المحاسبية الجيدة سواء من خلال الإسناد الخارجي لبعض وظائف المحاسبة أو من خلال تبني تكنولوجيا المعلومات والالتزام بتطبيق معايير التقرير المالي الدولية للمشروعات الصغيرة والمتوسطة وذلك لتطوير التقارير المالية لهذه المشروعات من لن الهن ناحية والحفاظ على استدامة أداءها من ناحية أخرى. ץ- قيام بورصـة النيل بتطوير مؤشر يتضـن أفضل ممارسـات الإفصـاح الاختياري في المشروعات الصغيرة والمتوسطة، وترتيبها من حيث الأفضلية وفقا لذلك، مـع منح حوافز للمشروعات التي تحقق أعلى مستوى إفصـاح على أن يعلن عن ذلك على الموقع الإلكتروني لبورصـة النيل وفي المقابل يتم فرض عقوبات على المشروعات التي ينخفض فيها مستوى إفصاحها عن حد معين. r- تفعيل دور مراقب الحسابات في التوكيد على المعلومات التي تتضمنها التقارير المالية للمشروعات الصغيرة والمتوسطة الحجم هو ما يعزز من ثقة أصحاب المصالح في تقارير هذه المشروعات ويسهل حصولها على التمويل اللازم. ع - ضرورة قيام هيئة الرقابة المالية بالتعاون مع مركز المديرين المصري بإصدار دليل حوكمة خاص بالثركات الصغيرة والمتوسطة الحجم على أن يتضمن أفضل ممارسات الحوكمة بطريقة مبسطة هردئ وأقل تعقيدًا عن الثركات الكبيرة الحجم بما يعزز من خصائص مجلس الإدارة (خاصسة استقلال مجلس الإدارة ولجان المراجعة). ه- ضـرورة قيام البنوك التجاريـة ومؤسسـات تمويـل المشروعات الصـيرة والمتوسطة بتوفير التمويـل اللازم لهذه المشروعات وخفض معدلات الفائدة على ما يقدم لها من قروض حيث تعتبر مشكلة

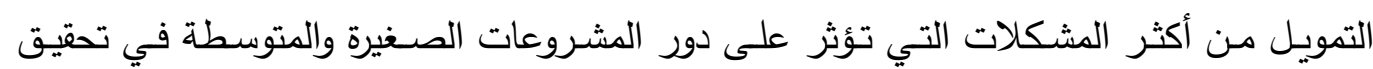
التتمية الاقتصادية. ؟- توجيـه نظـر المسـولين لأهميـة المشـروعات الصـغيرة والمتوســة وضـرورة العمـل على إزالــة المعوقات وحل المشكلات التي تواجه هذه المشروعات حتى تتمكن من القيام بالدور المنوط بها في تتمية الاقتصاد القومي المصري. 


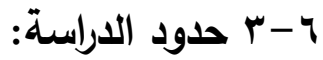

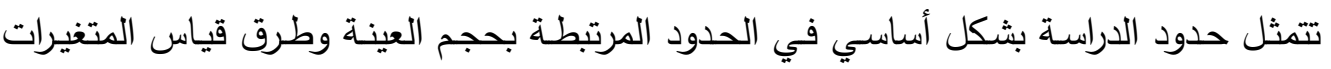
والأساليب الإحصائية المستخدمة، بالإضافة إلى أن الدراسة لم تتناول كافة العوامل المحددة لجودة بيئة

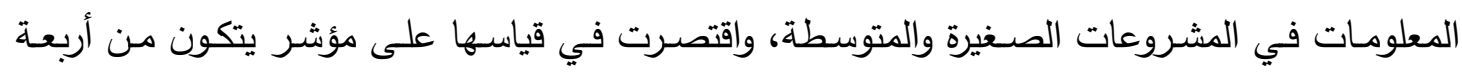

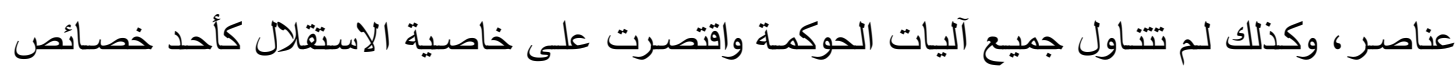

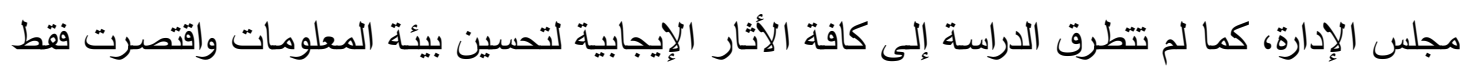
في الأثر على التمويل طويل الأجل، وتكلفة الدين.

\section{צ- - أتوجهات البحثية المستقبلية:}

تمثل الدراسة الحالية دعوة للباحثين في الأدب المحاسبي للقيام بدراسات أخرى مستقبلية في

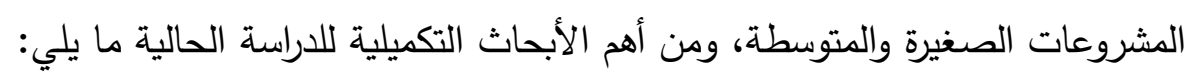

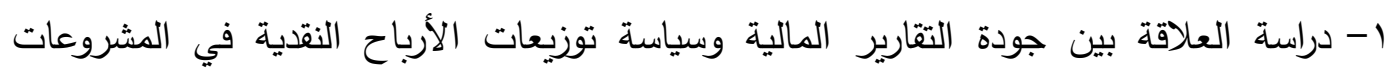
الصغيرة والمتوسطة.

r- دراسة أثر الإفصاح عن المسئولية الاجتماعية على التعثر المالي في المشروعات الصغيرة والمتوسطة. 


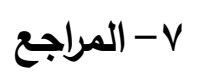

$$
\text { 1-v }
$$

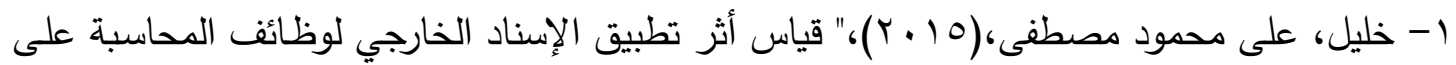

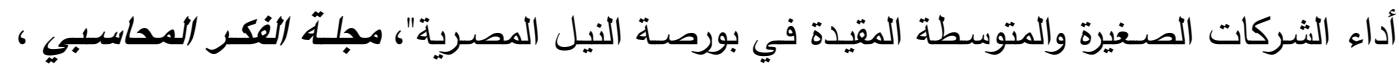

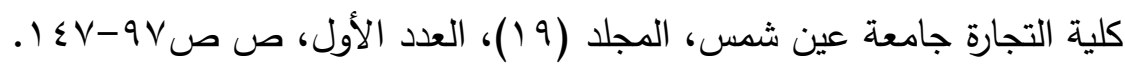

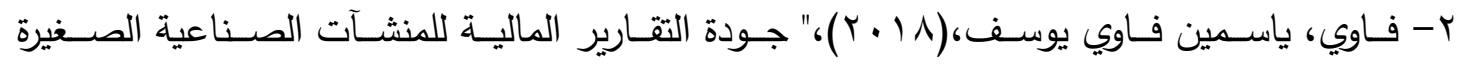

والمتوسطة SMEs في ضوء المعيار المحاسبي المصري رقم (VI) الصادر عام 10 ـ ب"، بحث

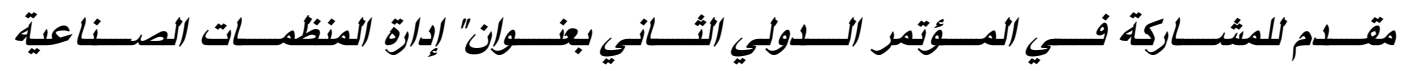

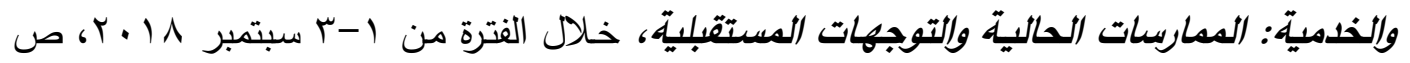

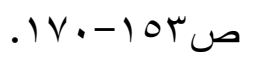

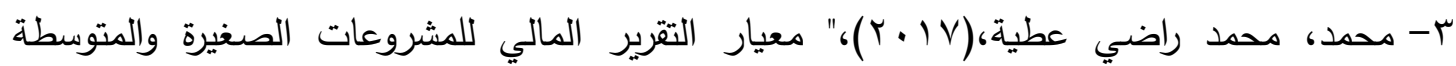

وزيادة جودة الإفصاح المحاسبي بالتطبيق على البيئة المصرية- دراسة (IFRS for SMES)

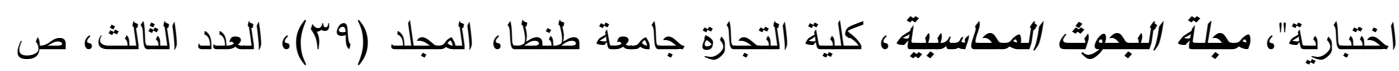

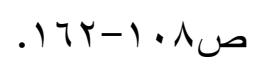

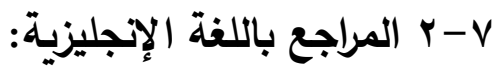

1- Abdulsaleh \& Worthington, A., ( 2013). Small and Medium-sized enterprises financing: A review of the literature. International Journal of Business and Management, 8 (14), 36-54.

2- $\quad$ Ale-Ebrahim, N., Ahmed, S., \& Taha, Z. (2010). Critical factors for new product developments in SMEs virtual team. African Journal of Business Management, 4(11), 2247-2257.

3- Allee, K.D. \& Yohn, T.L., (2009). The Demand for Financial Statements in an Unregulated Environment: An Examination of the Production and Use of Financial Statements by Privately Held Small Businesses. The accounting review, 84 (1), 1-25.

4- Anderson, R.C., Mansi, S.A. and Reeb, D.M. (2004). Board characteristics, accounting report integrity, and the cost of debt. Journal of accounting and Economics. 37, 315-342.

5- Armstrong, C.S., Guay, W.R. and Weber, J.P. (2010).The role of information and financial reporting in corporate governance and debt contracting. Journal of Accounting and Economics. 50(2), 179-234.

6- Bakhtiari, S. (2015). Productivity, outsourcing and exit: The case of Australian manufacturing. Small Business Economics, 44(2), 425-447.

7- $\quad$ Ball R and Shivakumar L (2005). Earnings quality in UK private firms: comparative loss recognition timeliness. Journal of Accounting and Economics, 39(1), 83-128. 
8- Ball R, Robin A and Sadka G (2008). Is financial reporting shaped by equity markets or by debt markets? An international study of timeliness and conservatism. Review of Accounting Studies, 13(2-3), 168-205.

9- $\quad$ Barrar, P., Wood, D., Jones, J., \& Vedovato, M. (2002). The efficiency of accounting service provision. Business Process Management Journal, 8(3), 195-217.

10- Barth, M., Landsman, M. and Lang, M. (2008).International Accounting Standards and Accounting Quality. Journal of Accounting Research, 46(3), 467-498.

11- Beck, T. and Demirguc-Kunt, A. (2006). Small and medium-size enterprises: Access to finance as a growth constraint, Journal of Banking and Finance, 30(11), 2931-2943.

12- Berger AN and Udell GF (2002). Small business credit availability and relationship lending: The importance of bank organizational structure. The economic journal, 112(477): F32-F53.

13- Berger, A. and Udell, G.F. (1998). The economics of small business finance: the roles of private equity and debt markets in the financial growth cycle. Journal of Banking and Finance, 22(6-8), 613-673.

14- Bertoni, M., \& De Rosa, B. (2010). The evolution of financial reporting for private entities in the European Union. Social Science Research Network. Retrieved on 3 agosto, 2011, from http://papers.ssrn.com/ sol3/papers.cfm?abstract_id=1536065.

15- Bharath, S. T., Sunder, J., \& Sunder, S. V. (2008). Accounting quality and debt contracting. The Accounting Review, 83(1), 1-28.

16- Binks, M. R., \& Ennew, C. T. (1996). Growing firms and the credit constraint. Small Business Economics, 8(1), 17-25.

17- Boone, J.P., Khurana, I.K. and Raman, K.K. (2010).Do the Big 4 and the Second-tier firms provide audits of similar quality?. Journal of Accounting Public Policy, 29(4), 330-352.

18- Bradshaw, M., Bens, D., Frost, C.A., Gordon, E., McVay, S., Miller, G., Pfeiffer, R., Plumlee,M.,Shakespeare, C.,Thomas, W. and Wong. F. (2014). Financial Reporting Policy Committee of the American Accounting Association's Financial Accounting and Reporting Section: Accounting Standard Setting for Private Companies, Accounting Horizons, 28(1), 175-192.

19- Brüggemann, U., Hitz, J-M. andSellhorn, T. (2013).Intended and Unintended Consequences of Mandatory IFRS Adoption: A Review of Extant Evidence and Suggestions for Future Research. European Accounting Review, 22(1), 1-37.

20- Byard, D., Li, Y. and Yu, Y. (2011).The Effect of Mandatory IFRS Adoption on Financial Analysts' Information Environment. Journal of Accounting Research, 49(1), 69-96.

21- Caramanis C and Lennox C. (2008). Audit effort and earnings management. Journal of Accounting and Economics. 45(1): 116-138.

22- Carvalho, C., \& Abramovay, R. (2004). O difícil e custoso acesso ao sistema financeiro. In C. A. Santos (Org.). Sebrae, Sistema financeiro e 
as micro e pequenas empresas: diagnósticos e perspectivas (2a ed., pp.17-45). Brasília: Sebrae.

23- Cassar G, Ittner CD and Cavalluzzo KS .(2015). Alternative information sources and information asymmetry reduction: Evidence from small business debt. Journal of Accounting and Economics. 59(2): 242-263.

24- Chen, F., Hope, O.-K., Li, Q. and Wang, X. (2011). Financial Reporting Quality and Investment Efficiency of Private Firms in Emerging Markets, The Accounting Review, 86(4), 1255-1288.

25- Christensen, H. B., Lee, E. and Walker, M. (2009). Do IFRS reconciliations convey information? The effect of debt contracting, Journal of Accounting Research, 47(5), 1167-1199.

26- Chua, J.H., Chrisman, J.J., Kellermanns, F. and Wu, Z. (2011).Family involvement and new venture debt financing. Journal of Business Venturing, 26, 472-488.

27- Collis J (2012) Determinants of voluntary audit and voluntary full accounts in micro and non-micro small companies in the UK. Accounting and Business Research. 42(4): 441-468.

28- Collis, J. and Jarvis, R., 2000. How owner-managers use accounts. London: ICAEW. Available from: http://www.icaew.com/en/technical/ research-and-academics/publications-and-projects / /media /Files/ Technical/Research-and-academics/publications-and projects/financialreporting-publications/how-owner-managers-use-accounts.ashx.

29- Collis, J., 2003. Directors' Views on Exemption from Statutory Audit. London: DTI, URN 03/1342. Available from: http://www.berr.gov.uk / files / file25971.pdf.

30- Collis, J., 2010. Audit exemption and the demand for voluntary audit - a comparative study of the UK and Denmark. International journal of auditing, 14 (2), 211-231.

31- Collis, J., Jarvis, R. and Skerratt, L., 2004. The demand for the audit in small companies in the UK. Accounting and business research, 34 (2), 87-100.

32- Coluzzi, C., Ferrando, A. and Martinez-Carrascal, C. (2012). Financing obstacles and growth: an analysis for Euro Area non-financial firms, European Journal of Finance, 18(3), 1-18.

33- Coppens L and Peek E .(2005). An analysis of earnings management by European private firms. Journal of International Accounting, Auditing and Taxation. 14(1): 1-17.

34- Daske, H., Hail, L., Leuz, C. and Verdi, R. (2008). Mandatory IFRS Reporting around the World: Early Evidence on the Economic Consequences, Journal of Accounting Research,46(5), 1085-1142.

35- Davila, T. (2005).An exploratory study on the emergence of management control systems: formalizing human resources in small growing firms, Accounting, Organization, and Society, 30(3), pp. 223248. 
36- Dechow PM, Ge W and Schrand C (2010). Understanding earnings quality: A review of the proxies, their determinants and their consequences. Journal of Accounting and Economics. 50(2), 344-401.

37- Degryse, H., de Goeij, P., \& Kappert, P. (2012). The impact of firm and industry characteristics on small firms' capital structure. Small Business Economics, 38(4), 431-447.

38- Diamond, D. W. and Verrecchia, R.E. (1991). Disclosure, liquidity, and the cost of capital, Journal of Finance,46(4), 1325-1359.

39- Easley, D., and O'Hara, M. (2004). Information and the cost of capital, Journal of Finance, 59(4), 1553-1583.

40- Eierle B (2008). Filing Practice of Small and Medium-sized Companies: Empirical Findings from Austria. International Small Business Journal. 26(4), 491-528.

41- Espino-Rodríguez, T. F., \& Padrón-Robaina, V. (2004). Outsourcing and its impact on operational objectives and performance: a study of hotels in the Canary Islands. Hospitality Management, 23, 287-306. http://dx.doi.org/10.1016/j.ijhm.2003.11.004.

42- $\quad$ Esuh, O. L. \& Adebayo, I. O. (2012). Is small and medium enterprises (SMEs) an entrepreneurship?. International Journal of Academic Research in Business \& Social Sciences, 2 (1), 487-496.

43- European Commission. (2003).SMEs and access to finance. The European Observatory for European SMEs, Brussels.

44- European Investment Bank. (2003).Bank survey evidence on bank lending to SMEs in the European Union. Economic and Financial Report .2003/01.

45- Evans L, Gebhardt G, Hoogendoorn M, Marton J, Di Pietra R, Mora A, Thinggård F, Vehmanen P and Wagenhofer A (2005). Problems and opportunities of an international financial reporting standard for small and medium-sized entities. The EAA FRSC's comment on the IASB's discussion paper. Accounting in Europe. 2(1): 23-45.

46- Everaert, P., Sarens, G., \& Rommel, J. (2007). Sourcing strategy of Belgian SMEs: Empirical evidence for the accounting services. Production Planning \& Control: The Management of Operations, 18(8), 716-725.

47- Everaert, P., Sarens, G., \& Rommel, J. (2010). Using Transaction Cost Economics to explain outsourcing of accounting. Small Bus Econ, 35(1), 93-112. http://dx.doi.org/10.1007/s11187-008-9149-3.

48- Ferrando, A., and Mulier, K. (2013).Do firms use the trade credit channel to manage growth?, Journal of Banking \& Finance, 37, 30353046.

49- Financial Reporting Council (2015). Improving the quality of reporting by smaller listed and AIM quoted companies: discussion paper on the FRC's findings and proposals, Financial Reporting Council, London.

50- Fortin, S. and Pittman, J.A. (2007).The Role of Auditor Choice in Debt Pricing in Private Firms, Contemporary Accounting Research, 24(3), 859-896. 
51- Francis, J., LaFond, R.Z., Olsson, P. and Schipper, K. (2005). The market pricing of accruals quality, Journal of Accounting and Economics, 39, 295-327.

52- $\quad$ Francis, J.R., Maydew, E.L. and Sparks, H.C. (1999).The role of Big 6 auditors in the credible reporting of accruals, Auditing: A Journal of Practice and Theory, 18(2), 17-34.

53- Franco, G., Gavious, I., Jin, J.Y. and Richardson, G.D. (2011).Do Private Company Targets that Hire Big 4 Auditors Receive Higher Proceeds?. Contemporary Accounting Research,28(1), 215-262.

54- Galindo, A. and Schiantarelli, F. (Eds.). (2003).Credit constraints and investment in Latin America. Inter-American Development Bank, Washington, DC.

55- García-Teruel PJ and Martínez-Solano P (2007). Short-term Debt in Spanish SMEs. International Small Business Journal .25(6): 579-602.

56- Ghosh AA and Moon D. (2010). Corporate debt financing and earnings quality. Journal of Business Finance \& Accounting. 37(5-6): 538-559.

57- Gilley, K., \& Rasheed, A. (2000). Making more by doing less: An analysis of outsourcing and its effect on firm performance. Journal of Management, 26(4), 763-790.

58- Glaum, M., Baetge, J., Grothe, A. and Oberdörster, T. (2013). Introduction to International Accounting Standards, Disclosure Quality and Accuracy of Analysts' Earnings Forecasts, European Accounting Review, 22(1), 79-116.

59- Gooderham, P. N., Tobiassen, A., Døving, E., \& Nordhaug, O. (2004). Accountants as sources of business advice for small firms. International Small Business Journal, 22(1), 5-22.

60- Gul FA, Chen CJ and Tsui JS (2003). Discretionary accounting accruals, managers' incentives, and audit fees. Contemporary accounting research. 20(3): 441-464.

61- He, X., Wong, T.J. and Young, D. (2012). Challenges for Implementation of Fair Value Accounting in Emerging Markets: Evidence from China, Contemporary Accounting Research, 29(2), 538562.

62- Healy PM and Wahlen JM (1999). A review of the earnings management literature and its implications for standard setting. Accounting horizons. 13(4): 365-383.

63- Herman, N. (2010). IFRS for SMEs: not for private American companies. The CPA Journal, 8(12), 11-12.

64- Höglund, H. \& Sundvik, D., (2016). Financial reporting quality and outsourcing of accounting tasks: Evidence from small private firms, Advances in Accounting, incorporating Advances in International Accounting, 35: 125-134.

65- Hope O-K, Thomas WB and Vyas D (2013). Financial reporting quality of US private and public firms. The Accounting Review. 88(5): 17151742. 
66- Hope, O. K., Thomas, W. B., \& Vyas, D. (2009). Transparency, ownership, and financing constraints in private firms. [Working Paper]. University of Toronto and University of Oklahoma.

67- Hope, O.-K.,Thomas, W.B. and Vyas, D. (2011). Financial credibility, ownership, and financing constraints in private firms, Journal of International Business Studies, 42(7), 935-957.

68- Horton, J., Serafeim, G. and Serafeim, I. (2013).Does Mandatory IFRS Adoption Improve the Information Environment?, Contemporary Accounting Research, 30(1), 388-423.

69- Huguet D and Gandía JL (2014). Cost of debt capital and audit in Spanish SMEs. Spanish Journal of Finance and Accounting/ Revista Espanola de Financiacion y Contabilidad .43(3): 266-289.

70- Huyghebaert, N. and Van de Gucht, L.M. (2007). The Determinants of Financial Structure: New Insights from Business Start-ups, European Financial Management, 13, 101-133.

71- IASB. (2009a). IFRS for SMEs - Project history. Retrieved from: http://ifrs.org/IFRS-for-SMEs/history/Pages/History.aspx.

72- IASB. (2015). International financial reporting standards (IFRS) for small and medium-sized entities (SME). Retrieved from: http://www.ifrs.org/issued-standards/ifrs-for-smes/.

73- Intrum Justitia (2005).European Payment Index: All time high number of insolvencies -Lower payment risks. Intrum Justitia, Stockholm, Sweden.

74- Isimoya, A. O. (2005). Nigerian Business Environment (1st eds). Lagos: Concept Publications Limited.

75- Ismail, N. A., \& King, M. (2005). Firm performance and AIS alignment in Malaysian SMEs. International Journal of Accounting Information Systems, 6, 241-259. http://dx.doi.org/10.1016/j.accinf.2005.09.001.

76- Jaggi, B., Leung, D. and Gul, F. (2009). Family control, board independence and earnings management: Evidence based on Hong Kong firms, Journal of Accounting Public Policy, 28(4), 281-300.

77- Jayabalan, J., Raman, M., Dorasamy, M., \& Ching, N. K. C. (2009). Outsourcing of Accounting Functions amongst SME Companies in Malaysia: An Exploratory Study. Accountancy Business and the Public Interest, 8(2), 96-114.

78- Kamyabi, Y., \& Devi, S. $(2011$ b). The Impact of Accounting Outsourcing on Iranian SME Performance: Transaction Cost Economics and Resource-Based Perspectives. World Applied Sciences Journal, 15(2), 244-252.

79- Kamyabi, Y., \& Devi, S. (2011a). An Empirical Investigation of Accounting Outsourcing in Iranian Investigation of Accounting Outsourcing in Iranian Based Views. International J. Business and Management, 6(3), 81-94.

80- Kamyabi, Y., \& Devi, S. (2011c). Use of Professional Accountants' Advisory Services and its Impact on SME Performance in an Emerging Economy: A Resource-based View. J. Management and Sustainability, $1(1), 43-55$. 
81- Kang, T., Krishnan, G.V., Wolfe, M.C. and Yi, H.S. (2012).The Impact of Eliminating the 20-F Reconciliation Requirement for IFRS Filers on Earnings Persistence and Information Uncertainty, Accounting Horizons, 26(4), 741-765.

82- Kim JB, Simunic DA, Stein MT and Yi CH (2011). Voluntary Audits and the Cost of Debt Capital for Privately Held Firms: Korean Evidence. Contemporary accounting research. 28(2): 585-615.

83- Kitching, J., Kašperová, E., Blackburn, R. and Collis, J., 2011. Small company abbreviated accounts: A regulatory burden or a vital disclosure? Edinburgh: Institute of Chartered Accountants in Scotland. ISBN 978-1-904574-80-4 EAN 9781904574804. Available from: http://www.icas.org.uk/site/cms/contentviewarticle.asp? article=7529.

84- Kolsi, M., \& Zehri, F. (2013). The determinants of IAS/IFRS adoption by emergent countries. In Working paper, Emirates College of Technology, Abu Dhabi.

85- Kotabe, M., \& Mol, M. J. (2009). Outsourcing and financial performance: A negative curvilinear effect. J. Purchasing and Supply Management, 15, 205-213. http://dx.doi.org/10.1016/ j.pursup.2009. 04.001 .

86- Krishnan GV (2003). Does Big 6 auditor industry expertise constrain earnings management? . Accounting horizons .17(Supplement): 1-16.

87- Lamminmaki, D. (2007). Outsourcing in Australian Hotels: A transaction cost economics perspective. J. Hospitality and Tourism Res., 31, 73-110. http://dx.doi.org/10.1177/1096348006296714.

88- Lamminmaki, D. (2008). Accounting and the management of outsourcing: An empirical study in the hotel industry. Management Accounting Res., 19, 163-181. http://dx.doi.org/10.1016/j.mar.2008. 02.002 .

89- Lang, M. \& Martin, R., 2017, The Trickle Down Effect - IFRS and accounting by SMEs, European Federation of Accountants and Auditors For SMES.

90- Lardon, A., \& Deloof, M. (2014). Financial disclosure by SMEs listed on a semi-regulated market: evidence from the Euronext Free Market. Small Business Economics, 42(2), 361-385.

91- Lennox, C.S. and Pittman, J.A., (2011). Voluntary Audits versus Mandatory Audits. The accounting review, 86 (5), 1655-1678.

92- Lenormand, G., Poulard, B., \& Touchais, L. (2012). Les IAS/IFRS. Revue Française de Gestion, 3(222), 55-66.

93- Leuz, C. and Verrecchia, R.V. (2000). The economic consequences of increased disclosure, Journal of Accounting Research,38, 91-124.

94- Litjens, R., Bissessur, S., Langendijk, H., \& Vergoossen, R. (2012). How do preparers perceive costs and benefits of IFRS for SMEs? Empirical evidence from the Netherlands. Accounting in Europe, 9(2), 227-250.

95- Luypaert M, Van Caneghem T and Van Uytbergen S (2015). Financial statement filing lags: An empirical analysis among small firms. 
International Small Business Journal doi: 10.1177/02662426155 69324.

96- Maffett, M. (2012).Financial reporting opacity and informed trading by international institutional investors, Journal of Accounting and Economics, 54(2-3), 201-220.

97- Mahmoodzadeh, E., Jalalinia, S., \& Yazdi, F. N. (2009). A business process outsourcing framework based on business process management and knowledge management. Business Process Management Journal, 15(6), 845-864. http://dx.doi.org/10.1108/14637150911003748.

98- Marriott, N., \& Marriott, P. (2000). Professional accountants and the development of a management accounting service for the small firm: Barriers and possibilities. Management Accounting Research, 11(4), 475-492.

99- Marriott, N., Collis, J. and Marriott, P., 2006. Qualitative review of the accounting and auditing needs of small and medium-sized companies and their stakeholders. London: Professional Oversight Board. Available from: http://www.frc.org.uk/documents/pagemanager/poba/Case\%20 studies\%20report.pdf

100- Martin, C. (2005). Accountancy practices and the provision of ownership succession advice (NO. 85). The Association of Chartered Certified Accountants.

101- McMahon RGP (1999). Financial Reporting to Financiers Australian Manufacturing SMEs. International Small Business Journal. 18(1): 35-52.

102- Minnis M (2011). The value of financial statement verification in debt financing: Evidence from private US firms. Journal of Accounting Research. 49(2): 457- 506.

103- Moro A, Fink M and Kautonen T (2014). How do banks assess entrepreneurial competence? The role of voluntary information disclosure. International Small Business Journal. 32(5): 525-544.

104- Morris, R. and Omrod, P., 1990. The Attitudes of Credit Analysts towards Reduced Disclosure by Small Companies. Annual Congress of the European Accounting Association, Budapest, April.

105- Myers JN, Myers LA and Omer TC (2003). Exploring the term of the auditor-client relationship and the quality of earnings: A case for mandatory auditor rotation?. The Accounting Review. 78(3): 779-799.

106- Nandan, R. (2010). Management accounting needs of SMEs and the role of professional accountants: A renewed research agenda. Journal of Applied Management Accounting Research (JAMAR), 8(1), 65-78.

107- Neag, R., Masca, E., \& Pascan, I. (2009). Actual aspects regarding the IFRS for SME-Opinions, debates and future developments. Annales Universitatis Apulensis Series Oeconomica, 11(1), 32-42.

108- Nelson, M.W., Elliot, J. A., \& Tarpley, R. L. (2002). Evidence from auditors aboutmanagers' and auditors' earnings management decisions. The Accounting Review, 77(s-1), 175-202. 
109- Newman A, Gunessee S and Hilton B .(2012). Applicability of financial theories of capital structure to the Chinese cultural context: A study of privately owned SMEs. International Small Business Journal, 30(1): $65-83$.

110- Niemi, L., Kinnunen, J., Ojala, H. and Troberg, P., (2012). Drivers of voluntary audit in Finland: To be or not to be audited?. Accounting and business research, 42, doi: 10.1080/00014788.2012.653742 .

111- Nwobu, O.; Faboyede, S. O.; Onwuelingo, A. T.,( 2015). The Role of Accounting Services in Small and Medium Scale Businesses in Nigeria. Journal of Accounting - Business \& Management. 22 (1), 55-63.

112- Ojala, H., Niskanen, M., Collis, J., \& Pajunen, K. (2014). Audit quality and decision-making in small companies. Managerial Auditing Journal, 29(9), 800-817.

113- Okoh, L. O. \& Uzoka, P. (2012). The Role of Accounting Information in the Survival of Small Scale Businesses in Warri, Delta State, Nigeria, International Journal of Economic Development Research and Investment. 3 (1),40-44.

114- Ortiz-Molina, H., \& Penas, M. F. (2008). Lending to small businesses: the role of loan maturity in addressing information problems. Small Business Economics, 30(4), 361-383.

115- Paananen, M., Renders, A., Blomkvist, M., (2016), Causes and Consequences of Improvements in the Information Environment for Swedish Small and Mid-Sized Firms, Accounting in Europe, 13 (1),143.

116- Pacter, P. (2004) Financial reporting: SMEs - Will the GAAP widen for SMEs?, Accountancy, 133, 118-119.

117- Pacter, P. (2009). IFRS for most private companies goes live. Financial Executive, 25(7), 28-30.

118- Perera, D., \& Chand, P. (2015). Issues in the adoption of international financial report-ing standards (IFRS) for small and medium-sized enterprises (SMEs). Advancesin Accounting, 31(1), 165-178.

119- Petersen, M.A. and Rajan, R.G. (1994).The Benefits of Lending Relationships: Evidence from Small Business Data, The Journal of Finance, 49(1), pp. 3-37.

120- Quagli, A., \& Paoloni, P. (2012). How is the IFRS for SME accepted in the European context? An analysis of the homogeneity among European countries, users and preparers in the European commission questionnaire. Advances in Accounting, 28(1), 147-156.

121- Quélin, B., \& Duhamel, F. (2003). Bringing together strategic outsourcing and corporate strategy: Outsourcing motives and risks. European Management Journal, 21(5), 647-661.

122- Quinn, J., \& Hilmer, F. (1994). Strategic outsourcing. Sloan Management Review, 35(1), 43-55.

123- Rennie MD and Senkow DW (2009) Financial Reporting for Private Companies: The Canadian Experience. Accounting perspectives. 8(1): 43-68. 
124- Riva, E. D. \& Salotti, B., 2015, Adoption of the International Accounting Standard by Small and Medium- Sized Entities and its Effects on Credit Granting, Revista Contabilidade \& Financas,69(26): 304-316.

125- Sian S and Roberts C .(2009). UK small owner-managed businesses: accounting and financial reporting needs. Journal of Small Business and Enterprise Development. 16(2): 289-305.

126- Skinner, D. J., \& Srinivasan, S. (2012). Audit quality and auditor reputation: Evidence from Japan. The Accounting Review, 87(5), 17371765.

127- Son DD, Marriott N and Marriott P (2006). Users' perceptions and uses of financial reports of small and medium companies (SMCs) in transitional economies: Qualitative evidence from Vietnam. Qualitative Research in Accounting \& Management. 3(3): 218-235.

128- Srinidhi B and Gul FA .(2007) .The differential effects of auditors' nonaudit and audit fees on accrual quality. Contemporary Accounting Research. 24(2): 595-629.

129- Tilley, H., \& Parrish, F. (2006). Small industries in developed countries. Australia: Wombat Press.

130- Tomkins, C., \& Green, R. (1988). An experiment in the use of data envelopment analysis for evaluating the efficiency of UK University Departments of Accounting. Financial Accountability \& Management, 4(2), 147-166.

131- Van Caneghem T and Van Campenhout G. (2012). Quantity and quality of information and SME financial structure. Small Business Economics. 39(2): 341-358.

132- Van Tendeloo, B., \& Vanstraelen, A. (2008). Earnings management and audit quality in Europe: Evidence from the private client segment market. The European Accounting Review, 17(3), 447-469.

133- Vander Bauwhede H, De Meyere M and Van Cauwenberge P (2015). Financial reporting quality and the cost of debt of SMEs. An Entrepreneurship Journal. 45(1): 149-164.

134- Weber, J., Willenborg, M., \& Zhang, J. (2008). Does auditor reputation matter? The case of KPMG Germany and ComROAD AG. Journal of Accounting Research, 46(4), 941-972.

135- Wilner, B. (2000). The Exploitation of Relationships in Financial Distress: The Case of Trade Credit, Journal of Finance, 55(1), 153178.

136- Wright, G. B., Fernandez, D., Burns, J., Hawkins, R., Hornsby, C., \& Patel, S. (2012). Big GAAP/little GAAP: will the debate never end?. Journal of Business \& Economics Research, 10(5), 291-302.

137- Zuelch, H., \& Burghardt, S. (2010). The granting of loans by German banks to SMEs against the background of international financial reporting. Journal of Applied Accounting Research, 10(1), 43-57. 